\title{
Harnessing the potential of vulnerability assessments for managing social- ecological systems
}

\author{
Lauric Thiault $^{1,2,3}, \underline{\text { Stacy D. Jupiter }}^{4}, \underline{\text { Johanna E. Johnson }}^{5,6}$, Joshua E. Cinner $^{7}$, Rebecca M. Jarvis $^{8}, \underline{\text { Scott F. Heron }}^{7,9}$, Joseph M. $^{\text {. }}$ \\ $\underline{\text { Maina }}^{10}$, Nadine A. Marshall ${ }^{11}, \underline{\text { Paul A. Marshall }}^{12,13}$ and $^{\text {Joachim Claudet }}{ }^{1,2}$
}

\begin{abstract}
The concept of vulnerability has broadened from initial applications in the fields of risk and hazards, human ecology and resilience to include the management of social-ecological systems (SES). We review how this concept has been operationalized in various contexts and identify opportunities and challenges to apply vulnerability assessments to SES management in the face of social, environmental, and climatic changes. We synthesize these lessons into a 12-step framework to help practitioners scope, design, operationalize, and implement vulnerability assessments that can effectively minimize exposure, reduce sensitivity, and enhance adaptive capacity. We describe the rationale, assumptions, and implications that underlie each step and highlight future directions that are critically needed to further enable vulnerability assessments to address real-world sustainability challenges. These include applying biocultural approaches, building knowledge about SES vulnerability to nonclimate stressors, and anticipating potential trade-offs and maladaptation. The framework presented provides a roadmap for the development of integrated vulnerability assessments that are robust, context-specific, and relevant to the management of SES.
\end{abstract}

Key Words: conservation planning; environmental management; risk; social-ecological systems; sustainability; vulnerability

\section{INTRODUCTION}

Vulnerability assessments can inform the development of adaptation and conservation policy and support the integration of socioeconomic and ecological factors into decision making (Metcalf et al. 2015). In effect, they help identify opportunities for strengthening the ability of a system to cope with external forces of change and minimize negative social or ecological outcomes. Research on vulnerability has traditionally been carried out within three linked fields, with varying understanding and use of the concept: (1) risk and hazard, involving anticipation of how environmental hazards, generally climate-related, are likely to impact human societies; (2) political ecology, the exploration of the social causes of differential susceptibility; and (3) resilience research, identification of underlying processes that determine the ability to cope and adapt to change (Turner et al. 2003a, Kasperson et al. 2005, Adger 2006, Eakin and Luers 2006).

Building on the conceptual and practical foundations provided by these complementary approaches, the Intergovernmental Panel on Climate Change (IPCC) presented a definition of vulnerability that is now the foundation of many vulnerability assessments: "vulnerability [to climate change] is the degree to which systems are susceptible to, and unable to cope with, adverse impacts [of climate change]" (IPCC 2007:48). In this definition, "systems" refers broadly to any social (where human organizations and institutions play a major role), natural (dominated by biological and biophysical processes), or socialecological systems (where both social and natural systems are interdependent). In practice, the term often designates relatively separate subsystem elements, also referred to as "components" in our approach. These may, for example, include individual resource users, human communities, the resources, or a species. Vulnerability has three dimensions defined in Table 1: exposure, sensitivity, and adaptive capacity. Vulnerability assessment can thus be viewed as an analytical exercise whose goal is to assess exposure, sensitivity, and adaptive capacity of one or more valued attribute(s), e.g., well-being, health, biomass, productivity, or condition, of one or more system component(s) to one or more stressor(s) (Tonmoy et al. 2014).

As management and conservation move toward more holistic and integrative approaches, and more quantitative datasets and model outputs from multidisciplinary projects become available (Guerrero et al. 2018), efforts to assess vulnerability have gained attention in relation to SES. Vulnerability assessments are especially helpful for identifying vulnerable components or places within the SES (vulnerability "hotspots") as a basis for better understanding of structural deficiencies (vulnerability "sources") and for informing management prioritization and design (Cinner et al. 2013a, b, Foden et al. 2013, Maina et al. 2016, Johnson and Welch 2016, Smith et al. 2016, Thiault et al. 2018a). As a result, they can help establish management and planning priorities (Aretano et al. 2015, Mora et al. 2015, Thiault et al. 2018a, Bourgoin et al. 2020, Lapola et al. 2020), assist in informing and designing management strategies and interventions (Cinner et al. 2012, Johnson and Welch 2016, Humphries et al. 2019, Thiault et al. 2020), set a baseline and assess change (Fawcett et al. 2017,

\footnotetext{
${ }^{1}$ National Center for Scientific Research, PSL Université Paris, CRIOBE, USR 3278 CNRS-EPHE-UPVD, Maison des Océans, Paris, France, ${ }^{2}$ Laboratoire d'Excellence CORAIL, Moorea, French Polynesia, ${ }^{3}$ Moana Ecologic, Rocbaron, France, ${ }^{4}$ Wildlife Conservation Society, Melanesia Program, Suva, Fiji, ${ }^{5} \mathrm{C}_{2} \mathrm{O}$ Coasts Climate Oceans, Vanuatu \& Cairns, Australia, ${ }^{6}$ College of Marine \& Environmental Sciences, James Cook University, Cairns, QLD Australia, ${ }^{7}$ Australian Research Council Centre of Excellence for Coral Reef Studies, James Cook University, Townsville, QLD Australia, ${ }^{8}$ Te Kura Pūtaiao - School of Science, Te Wānanga Aronui o Tāmaki Makau Rau - Auckland University of Technology, Tāmaki Makaurau - Auckland, Aotearoa New Zealand, ${ }^{9}$ Physics and Marine Geophysical Laboratory, James Cook University, Townsville, QLD, Australia, ${ }^{10}$ Faculty of Science and Engineering, Department of Earth and Environmental Sciences, Macquarie University, Sydney, New South Wales, Australia, ${ }^{11}$ CSIRO Land and Water, James Cook University, Townsville, QLD, Australia, ${ }^{12}$ Centre for Tropical Water and Aquatic Ecosystem Research, James Cook University, Australia, ${ }^{13}$ Environment Department, NEOM, Saudi Arabia
} 
Table 1. Glossary of terms with definitions adapted from the primary literature and illustrative examples from social (S) and ecological (E) systems.

\begin{tabular}{|c|c|c|}
\hline Term & Definition & Social (S) and ecological (E) examples \\
\hline Vulnerability & $\begin{array}{l}\text { Degree to which a component(s)' attribute(s) is (are) } \\
\text { susceptible to, or unable to cope with, adverse effects of one } \\
\text { or more stressors (modified from IPCC 2007). Vulnerability } \\
\text { has three dimensions: exposure, sensitivity, and adaptive } \\
\text { capacity. }\end{array}$ & Vulnerability of [component]'s [attribute] to [stressor]. \\
\hline Vulnerability assessment & $\begin{array}{l}\text { Analytical exercise whose goal is to assess vulnerability of a } \\
\text { valued attribute of one or more system's component(s) to one } \\
\text { or more stressor(s) (Tonmoy et al. 2014), often with the aim } \\
\text { to inform management and decision making. }\end{array}$ & $\begin{array}{l}\text { Multidimensional models (Pacifici et al. 2015), fuzzy cognitive } \\
\text { mapping (Singh and Nair 2014), scenarios (Hallegatte et al. } \\
\text { 2011), criteria-based assessments (Cinner et al. 2013a, } \\
\text { Johnson et al. 2016). }\end{array}$ \\
\hline Component & $\begin{array}{l}\text { Subsystem entity that is contained within the system of } \\
\text { interest. }\end{array}$ & $\begin{array}{l}\text { S: Individuals, households, communities, countries. } \\
\text { E: Species, stocks, habitats, ecosystems, eco-regions. }\end{array}$ \\
\hline Attribute & $\begin{array}{l}\text { Quality or feature inherent to the system's component likely } \\
\text { to be affected by a stressor. Change in a component's } \\
\text { attribute following exposure may provide a measure of } \\
\text { vulnerability outcome. }\end{array}$ & $\begin{array}{l}\text { S: Household well-being, community health. } \\
\text { E: Species biomass, stock productivity, ecosystem condition. }\end{array}$ \\
\hline Stressor & $\begin{array}{l}\text { Threat to a component. Either a major spike in pressure } \\
\text { (pulse) beyond the normal range of variability in which the } \\
\text { system operates, or a continuous or slow onset pressure } \\
\text { (press), commonly within the range of normal variability } \\
\text { (adapted from Turner et al. } 2003 a \text { ). }\end{array}$ & $\begin{array}{l}\text { S: Economic/market shocks (pulse), population growth (press } \\
\text { or pulse), coup d'état (pulse). } \\
\text { E: Tropical cyclone (pulse), sea level rise (press), changing } \\
\text { water quality (pulse or press). }\end{array}$ \\
\hline Exposure & $\begin{array}{l}\text { Nature and degree to which a component is in contact with, } \\
\text { or subject to, a stressor (IPCC 2001, Kasperson et al. 2005, } \\
\text { Adger 2006, Gallopín 2006). }\end{array}$ & $\begin{array}{l}\text { Magnitude, frequency, duration, and/or extent of [stressor] } \\
\text { experienced by [component]. }\end{array}$ \\
\hline Sensitivity & $\begin{array}{l}\text { Conditions determining the degree to which a component is } \\
\text { directly or indirectly altered or modified in the short term by } \\
\text { stressor exposure (modified from IPCC 2001, 2007, Bousquet } \\
\text { et al. 2015). }\end{array}$ & $\begin{array}{l}\text { S: Economic, demographic, psychological, and cultural } \\
\text { dependency (Marshall et al. 2017) } \\
\text { E: Specialization, dependence on environmental triggers, } \\
\text { dependence on interspecific interactions [likely to be disrupted } \\
\text { by stressor], rarity (Foden et al. 2013). }\end{array}$ \\
\hline Adaptive capacity & $\begin{array}{l}\text { Latent ability to implement effective responses to changes by } \\
\text { minimizing, coping with, or recovering from the potential } \\
\text { impacts of a stressor (Whitney et al. 2017, Cinner et al. 2018). }\end{array}$ & $\begin{array}{l}\text { S: Assets, flexibility, organization, learning, agency (Cinner et } \\
\text { al. 2018). } \\
\text { E: Life-history traits, genetic variation and evolvability, } \\
\text { phenotypic plasticity, (Nicotra et al. 2015). }\end{array}$ \\
\hline
\end{tabular}

Thiault et al. 2018b), inform sectoral programming (Ayers and Huq 2009, Cinner et al. 2012), or conduct scenario analysis (Hallegatte et al. 2011). Vulnerability assessments are also increasingly used as a common framework or tool for resiliencebased management and adaptation policy (Anthony et al. 2015, Mcleod et al. 2019). For example, various Pacific Island countries have implemented integrated vulnerability assessments with the aim to improve multisector coordination, strategically tailor interventions, and prioritize management effort and resource allocation (SPC-SPREP-GIZ 2016) and, in some cases, address specific issues such as food security (Bell and Taylor 2015, Bell et al. 2018).

Although originally centered on the impacts of climate-related stressors on human societies, vulnerability has come to increasingly overlap with key themes of the contemporary sustainability narratives, including human-nature interactions, complex systems science, global change, and ecological resilience and adaptation (Clark and Dickson 2003, Turner et al. 2003a, Folke et al. 2016). For example, vulnerability is increasingly integrated within approaches that consider more complex system dynamics such as cross-scalar influences, telecoupling, and multiple stressors (O'Brien and Leichenko 2000, Turner et al. 2003b, O'Brien et al. 2004, Belliveau et al. 2006, Tschakert 2007, Adger et al. 2009, McDowell and Hess 2012, Debortoli et al. 2018, Huynh and Stringer 2018, Naylor et al. 2020). Likewise, the emergent concept of social-ecological vulnerability (Marshall et al. 2009, Cinner et al. 2013b, Maina et al. 2016, Berrouet et al. 2018, Thiault et al. 2018a, $b$, Depietri 2020) echoes the increasingly mainstream recognition that people and nature are interdependent, because people are part of ecosystems and shape them, but are also fundamentally dependent on the capacity of these systems to support wellbeing and development (Fischer et al. 2015, Lebot and Siméoni 2015, Aswani et al. 2018, Ticktin et al. 2018, IPBES 2019).

Scholars exploring SES vulnerability have made great strides toward identifying key processes affecting system sustainability. But despite the potential of the vulnerability concept to tackle contemporary management problems, barriers continue to prevent uptake by policy makers and managers (Table 2). The result is that too few assessments lead to tangible outcomes or actions to reduce vulnerability. The lack of comprehensive, widely applicable, and reliable guidance to accompany both analyses and programmatic efforts for vulnerability assessments has raised concerns about their suitability to fulfill stated objectives, such as communicating risk, rationalizing policy decisions, and monitoring the effect of management interventions (Füssel 2007, Hinkel 2011, Comte et al. 2019).

Our goal is two-fold. First, we aim to make vulnerability assessments more readily applicable, to foster their use for knowledge accumulation and engagement with key stakeholders, 
Table 2. Challenges for considering vulnerability assessments in decision making.

\begin{tabular}{|c|c|c|}
\hline Challenges & $\begin{array}{l}\text { Opportunities for addressing } \\
\text { challenges (relevant steps) }\end{array}$ & References \\
\hline $\begin{array}{l}\text { - Vulnerability research provides a static } \\
\text { understanding of typically dynamic problems. }\end{array}$ & $\begin{array}{l}\text { - Use a longitudinal study design by repeating vulnerability assessments } \\
\text { over time }(1-4 ; 8 ; 10) \text {. } \\
\text { - Employ visualization and analytical tools that can illustrate vulnerability } \\
\text { and associated components across space and time }(8 ; 10 ; 11) \text {. }\end{array}$ & $\begin{array}{l}\text { (Lemos et al. 2016, Fawcett et } \\
\text { al. 2017, Thiault et al. 2018b) }\end{array}$ \\
\hline $\begin{array}{l}\text { - Indicators oversimplify complex processes } \\
\text { leading to vulnerability. }\end{array}$ & $\begin{array}{l}\text { - Use multiple indicators from various data sources and knowledge } \\
\text { systems for triangulation and maximum accuracy }(5-8) \text {. }\end{array}$ & $\begin{array}{l}\text { (Hinkel 2011, Debortoli et al. } \\
\text { 2018, Cochrane et al. 2019, } \\
\text { Naylor et al. 2020) }\end{array}$ \\
\hline $\begin{array}{l}\text { - Assumptions of simple linear relationships } \\
\text { between indicators and vulnerability that do } \\
\text { not reflect the dynamic processes driving } \\
\text { vulnerability. }\end{array}$ & $\begin{array}{l}\text { - Adapt indicators to the system and assessment objectives }(5) \text {. } \\
\text { - Be explicit about the assumptions and limitations underpinning the } \\
\text { indicators selected }(5-11) \text {. } \\
\text { - Clearly indicate the overall objective and perspective driving the } \\
\text { assessment (socioeconomic, ecological, etc.) and how interactions } \\
\text { between the various system's components are considered }(1-2 ; 4) \text {. } \\
\text { - Formulate algorithms that best represent the relationship among } \\
\text { vulnerability dimensions and indicators }(4 ; 8-10) \text {. }\end{array}$ & \\
\hline $\begin{array}{l}\text { - Elements of vulnerability vary according to the } \\
\text { context, scale, and study perspective. }\end{array}$ & $\begin{array}{l}\text { - Develop lists of contributors to a system's vulnerability (e.g., dimensions } \\
\text { of exposure, sensitivity, and adaptive capacity, and their subelements) in } \\
\text { various contexts and scales, and use them to guide the selection of } \\
\text { locally relevant indicators (4-5). } \\
\text { - Use large-scale vulnerability assessments to provide a motivation for } \\
\text { more detailed, contextual analyses of the place-based elements of } \\
\text { vulnerability at smaller scales (1-12). }\end{array}$ & $\begin{array}{l}\text { (Hinkel 2011, Marshall et al. } \\
\text { 2017, Cinner et al. 2018) }\end{array}$ \\
\hline $\begin{array}{l}\text { - Vulnerability assessments rely preferentially } \\
\text { upon specialized, academic knowledge and } \\
\text { insufficiently consider other key stakeholders. }\end{array}$ & $\begin{array}{l}\text { - Encourage stakeholder input and participation from diverse knowledge } \\
\text { systems as early as possible }(1-12) \text {. } \\
\text { Be consistent with local terminology and ontologies and use } \\
\text { nontechnical language where possible }(1-12) \text {. }\end{array}$ & $\begin{array}{l}\text { (O’Brien et al. 2007, Ford et } \\
\text { al. 2013, Sterling et al. 2017) }\end{array}$ \\
\hline $\begin{array}{l}\text { - Vulnerability terminology has a negative } \\
\text { connotation and is disempowering to local } \\
\text { people by labeling them as "vulnerable." }\end{array}$ & $\begin{array}{l}\text { - Be mindful of vulnerability terminology. "Vulnerability" and other } \\
\text { negatively valenced terms should be used within academic and } \\
\text { government circles but not in actual research and communication with } \\
\text { local people (10-12). } \\
\text { - Highlight empowering elements such as experience, adaptive capacity, or } \\
\text { resilience when working and communicating with local people (11). }\end{array}$ & $\begin{array}{l}\text { (Haalboom and Natcher } \\
\text { 2012, Ford et al. 2013) }\end{array}$ \\
\hline $\begin{array}{l}\text { - Vulnerability gives too little attention to the } \\
\text { underlying drivers that shape exposure- } \\
\text { sensitivities and adaptations. } \\
\text { - Elements of vulnerability do not carry equal } \\
\text { weight between contexts. }\end{array}$ & $\begin{array}{l}\text { Draw greater attention to the socioeconomic, political, governance, and } \\
\text { cultural contexts that shape how stressors are experienced and } \\
\text { responded to, for example through participatory approaches }(4 ; 10-12) \text {. } \\
\text { - Use local expert judgement, multicriteria decision techniques, and other } \\
\text { approaches that are available to quantify the relative contribution of } \\
\text { individual indicators when place-specific, empirical weights are not } \\
\text { available }(6-8) \text {. }\end{array}$ & $\begin{array}{l}\text { (Eakin and Luers 2006, Bunce } \\
\text { et al. 2010, Cameron 2012, } \\
\text { Thomas and Warner 2019) } \\
\text { (Füssel 2007, Eakin and } \\
\text { Bojórquez-Tapia 2008, } \\
\text { Thiault et al. 2019b) }\end{array}$ \\
\hline $\begin{array}{l}\text { - Vulnerability lacks clarity on the relative } \\
\text { importance of each indicator. }\end{array}$ & - Apply sensitivity and uncertainty analyses (9). & \\
\hline
\end{tabular}

and to aid information synthesis and generalization to support decision making. To this end, we present a 12-step framework that guides practitioners to understand and conduct a vulnerability assessment. This framework synthesizes the different approaches that have been used to evaluate vulnerability in SES and highlights current best practices. Second, we propose new directions for research and application.

\section{ASSESSING VULNERABILITY IN SOCIAL- ECOLOGICAL SYSTEMS}

We suggest that practitioners attempting to assess vulnerability of SES should apply 12 steps dividing across four phases: scoping, design, operationalization, and implementation (Fig. 1). Each phase comprises multiple steps for which we describe the overall rationale and review relevant approaches employed to date, their assumptions, and potential shortcomings. The framework is presented as a guide, helping to characterize important steps and navigate key challenges, based on an extensive review of the literature and our experiences in applying vulnerability assessments in different settings. Although the sequence of steps reflects the general progression of the assessment, we emphasize that applying this framework should remain as iterative as possible to allow new information, shortcomings, and obstacles to be identified, addressed, and incorporated. Vulnerability assessments encompass a broad range of approaches (Brugère and De Young 2015, Foden et al. 2019), but here, we focus on those relying on quantitative, numerical data rather than qualitative ones.

\section{Scope (Phase A)}

The point of entry to every vulnerability assessment begins by clearly articulating the objectives, the spatial and temporal boundaries, the system components being assessed, and the available data and resources. This first phase lays the foundation for the rest of the vulnerability assessment. If relevant, participation of stakeholders should thus be considered as early as possible and throughout the process in order to integrate their perspectives before the assessment focus and pathway are fixed. 
Fig. 1. Flowchart of the four phases (A-D) and 12 steps (1-12) for conducting robust, context-specific, and policy relevant vulnerability assessments of social-ecological systems. The 12 steps are interlinked and allow for iterative learning opportunities; feedbacks can occur among most of the steps, not just the neighboring ones graphically represented by dashed arrows.

scope

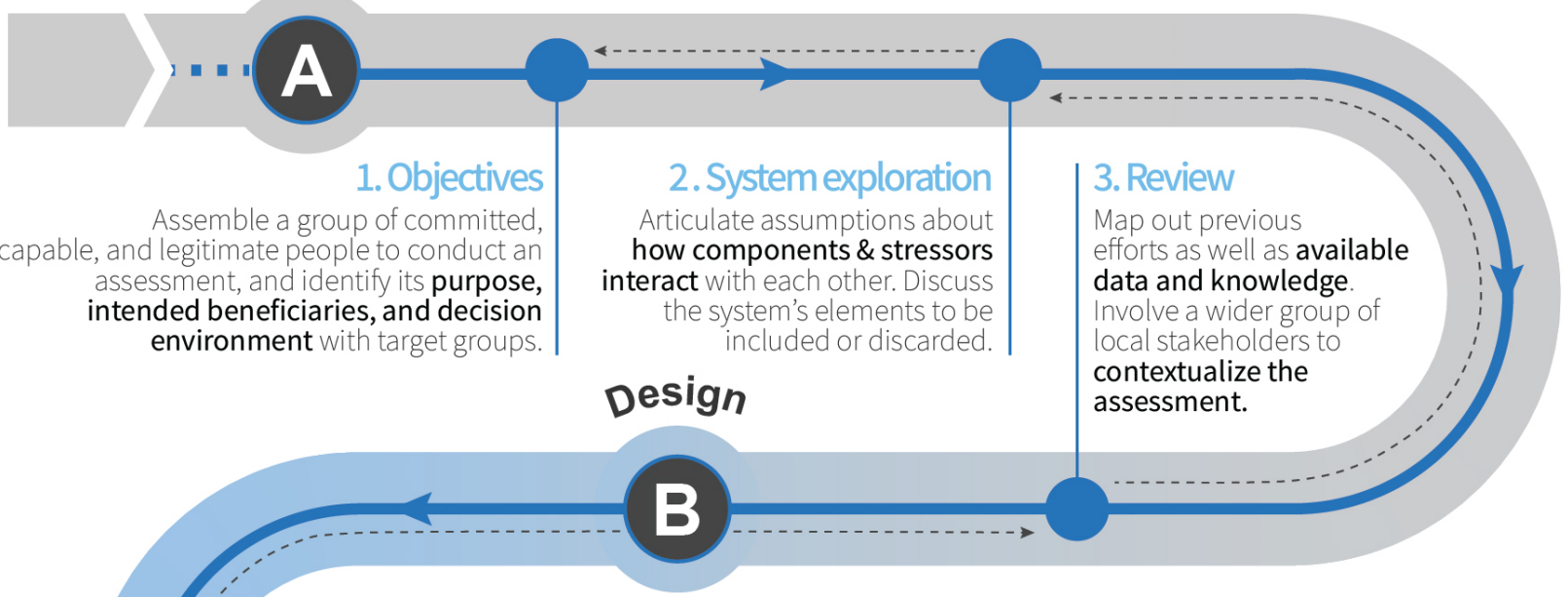

\section{- \\ (Co-)create a conceptual model of system vulnerability.} Describe the links between exposure, sensitivity, and adaptive capacity according to the system understanding. system's elements to be included or discarded.
Map out previous efforts as well as available data and knowledge volve a wider group of contextualize the assessment.

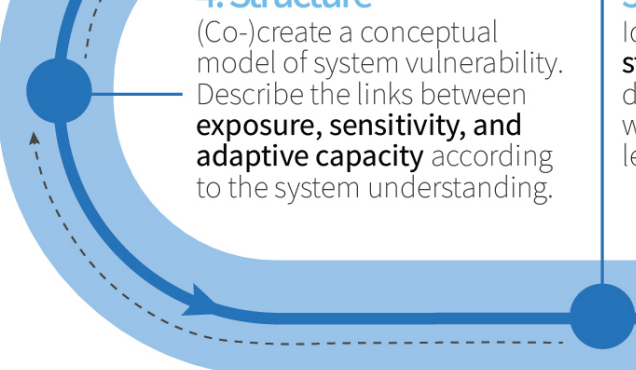

\section{Indicators}

Identify context-grounded indicators with stakeholders for each domain and

dimension of vulnerability. Be explicit about what is captured and what is left out.

\section{Data collection}

Consider the most appropriate way to collect data. Ensure that ethical considerations have been included and embrace coproduction when possible.

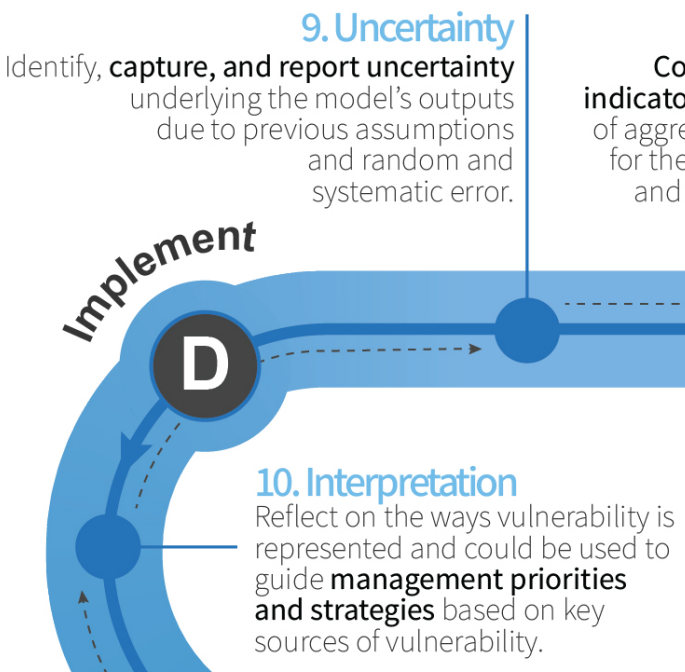

8. Integration Combine standardized dicators at the desired level aggregation by accounting eir relative importance d the way they interact.
7. Standardization

Transform and rescale the indicators to handle data skewness while ensuring that rea differences are stil well represented.
11. Communication Identify focal points to communicate results to specific audiences and be consistent with local terminology and onto logies.

\section{Learning}

Ensure that the methods are transparent and the results replicable to facilitate uptake and inspire confidence in the outputs. 
This means, (1) systematically representing stakeholders (step 1); (2) setting clear objectives (step 2); (3) using relevant methodologies (steps 3-6; 10-12); (4) ensuring opportunities for co-ownership (steps 10-12); and (5) reflecting on processes and outcomes (Reed 2008, Talley et al. 2016).

\section{Step 1: Objectives}

Vulnerability assessments need to be more than an academic exercise, with greater application and utility for decision making. To become more widely and effectively applied, they should involve a core group of people that can drive the process forward, manage information, deliberate, and act on behalf of the wider target group that is affected by the process. They should lead to implementation of identified actions and strategies. Although every vulnerability assessment is unique, they always involve compiling, analyzing, and synthesizing large amounts of data and information of different types (steps 5-10), which will require people with the capacity to organize and make use and sense of this information. Practitioners have skills and experience in designing and implementing programs on the ground and know how to generate outcomes in complex settings. Their expertise will help in articulating the specific purpose of the assessment and identifying the general decision context and specific trigger points for action within existing regulatory frameworks (step 10). In addition, people who have the capacity to reach out and talk to multiple stakeholders, explain the rationale for and outcomes of the process, and who are also good at listening to stakeholder input, are extremely valuable, especially during steps 1-6 and 10-12.

Once this core team is assembled, it needs to develop common principles for "good practice" in carrying out vulnerability assessments. These should include identifying, differentiating, and investigating relationships between stakeholders to decide who, when, to what extent, and why to engage with a particular group or not (i.e., steps 1-6 and 10-12); ensuring free, prior, and informed consent in data collection (step 6); consideration of gender and social inclusion and human rights approaches in identified interventions (step 10); and maintaining confidentiality of data from affected populations (step 11; Reed et al. 2009).

This first step also requires examining the specific needs of intended beneficiaries, identifying the main questions to be answered, and determining the time frame for the assessment, e.g., are the results going to inform short-term decisions and actions, or medium- to long-term planning? It is critical not to overlook biases that may arise when making such high-level decisions. The theory of boundary critique indeed suggests that the ways in which people or groups make choices about the above should be critically examined because individuals' understanding of any situation is inherently incomplete (Ulrich 1995, Midgley 2000). The resulting decisions are therefore based on a "selective application of knowledge" that may lead to the marginalization of some stakeholder groups and the issues that concern them. Choices made about the issues above should thus ensure equitable inclusion of all stakeholders potentially affected by the process and its outcomes. This can be achieved through approaches such as critical system heuristics (CSH; Ulrich 1987), which provides both the involved core team and stakeholders with a framework of questions to systematically examine the assessment's sources of motivation, power, knowledge, and legitimacy in the system of interest. Throughout a series of questions, what counts as relevant knowledge, adequate values, or "improvement" may be discussed and challenged, leading to a more participatory approach (as opposed to expert-driven) where those people with less power in the system have a voice in the process (Table 2).

\section{Step 2: System exploration}

This step is about framing the vulnerability assessment. It requires describing explicitly the key elements of the SES to be accounted for, and articulating assumptions about how SES components and stressors interact. Specifically, this step includes identifying key component(s) (vulnerability of what?), the stressor(s) (vulnerability to what?) and the pathways through which system components are affected by the stressor(s). For example, in the vulnerability framework developed by Cinner et al. (2012), the authors decided to explicitly focus on vulnerability of coupled coral reef SES to climate change impacts at the community level. Although the authors acknowledged that multiple factors can affect coral reef SES, they explicitly focused their analysis on pathways to direct ecological impact from temperature-induced bleaching and mortality of reef-building corals (ecological vulnerability) and associated loss of ecosystem services (social vulnerability).

Through this second step, the core team thus makes important decisions on what is considered relevant, provisionally deciding what should be included and what should be left out, eventually arriving at a shared conceptual understanding of the identity of the system (Binder et al. 2013). Coconceptualizing the key elements of the system with affected stakeholders is therefore warranted in order to ensure that their needs and perspective are considered. Collaborative systems mapping via tools such as mind mapping, causal diagrams, or fuzzy cognitive mapping provide avenues to achieve this (Voinov and Bousquet 2010). Because vulnerability involves a particular terminology, and the assessment is a collaborative endeavor, developing system literacy may be warranted to discuss and reflect collectively on the key concepts. To help in this process, we provide definitions and examples of key terms and concepts in Table 1.

Another key issue to consider during this initial system exploration is the spatial and temporal scale of the assessment (Huynh and Stringer 2018). Assessment scales need to correspond to those of the underlying processes affecting the outcome and time horizons of the management decisions in order to be compatible with the objectives (step 1). For example, if the objective is to prioritize national implementation of a certain policy, e.g., identifying spatial location of protected areas, based on current vulnerability, then the assessment could be static and remain constrained to national boundaries. On the other hand, if the objective is about assessing system response to a policy, then repeated assessments involving two or more snapshots will be warranted to capture dynamic feedback.

Step 3: Review

Each assessment varies not only in the type of output, but also in input requirements. Once the objectives are defined and the key components and stressor(s) have been clearly articulated, it is important to map out previous efforts and projects that have had similar objectives. This process will: assist in planning for data collection (e.g., prioritizing resource allocation for new primary data sources) and analysis (e.g., identifying technical capacities needed); create an evidence base for evaluating system component 
responses to changed conditions; assist in aggregating indicators; and may lead to re-evaluation of assessment objectives and scope (step 1). Beyond the people directing the assessment, a variety of stakeholders may be involved to assist in this step, if not involved previously. Decision makers, managers, resource users, opinion leaders, scientists, and holders of traditional knowledge can, among others, provide important data and sociocultural and political contexts (Reed 2008, Skroblin et al. 2019). The degree of engagement with these stakeholders will depend on the specific circumstances and needs, though knowledge coproduction literature suggests that incorporating a diversity of perspectives can lead to a richer understanding of system components and interactions (Armitage et al. 2011, Norström et al. 2020). In addition, the right approach for any particular assessment will depend on the overall objectives set in step 1, on the local context and on the level of resources (data, expertise, time, funding) available. It is therefore important to ensure that the time and resources available for the assessment are consistent with the objectives.

\section{Design (Phase B)}

Reflecting on the objectives, system model, and available resources enables a strategic approach to designing the vulnerability assessment. Practitioners can build on the knowledge generated in the scoping phase to identify the most relevant appropriate assessment structure and design relevant indicators. The choices made at all these steps should be justified and documented for transparency and replicability (step 12).

\section{Step 4: Model structure}

We propose that quantitative vulnerability assessments should include at least three nested layers of increasing detail: dimensions, domains, and indicators, which comprehensively incorporate relevant theories and context-grounded information (Box 1). The model structure describes high-level interactions, generally among social and/or ecological dimensions, and helps translate the system understanding (step 2) into a causal model of vulnerability. The model structure is the backbone of the vulnerability assessment. Its choice is therefore important because it shapes the outputs that will be derived from the assessment.

\section{Box 1:}

Dimensions, domains, and indicators of vulnerability.

A vulnerability assessment should be capable of determining what makes each case unique and what makes each case generalized and comparable across settings. We propose that vulnerability assessments incorporate three nested layers that vary in the specificity of their definition: dimensions (generic), domains (moving from generic to specific), and indicators (contextspecific).

Vulnerability comprises three broad dimensions: exposure, sensitivity, and adaptive capacity (Table 1). All three dimensions influence vulnerability but, especially in social-ecological vulnerability assessments, the division between these dimensions is not always clear. Because dimensions provide the higher level (first tier) underpinnings for implementing vulnerability-based management, i.e., reducing exposure, decreasing sensitivity, and/ or building adaptive capacity, it is crucial that the meaning of each dimension within the particular context of the analysis is clearly stated.
Domains break down each dimension into the features that moderate, or contribute to vulnerability. The domains are the features of the systems' component(s) that are most critical to influencing vulnerability in the general context of the study (described during the scoping phase). They enable practitioners to identify parts of the dimensions that are contributing the most to overall vulnerability, or which could benefit from efforts to reduce vulnerability. We consider domains to be heuristics that help scientists and practitioners organize their inquiries of vulnerability. Although there are no incorrect domains, it is crucial that they fit the context of the study system and location, and are anchored in relevant theories.

Building on decades of empirical and theoretical work, authors have indeed proposed a variety of domains to characterize dimensions of vulnerability. For example, in the context of climate change, exposure can be based on environmental variables/ stressors likely to impact system components (Mora et al. 2018). These stressors typically fall into either press (chronic) or pulse (acute) domains (Anthony et al. 2015). Examples of climate stressors used to describe indicators may include precipitation change (press) and extreme marine heat events (pulse; Day et al. 2019; Fig 2). In addition to climate stressors, exposure domains may derive from environmental, economic, or other external pressures. Marshall et al. (2017) proposed that social sensitivity to environmental change be disaggregated into four domains (economic dependency, demographic dependency, psychological dependency, and cultural dependency), and Cinner et al. (2018) that social adaptive capacity relied on five domains (assets, flexibility, social organization, learning, and agency; Fig 2). Likewise, a number of studies have developed domains for ecological components (Weißhuhn et al. 2018, Foden et al. 2019). For example, still in the context of climate change, Foden et al. (2013) proposed four domains of ecological sensitivity (specialization, dependence on environmental triggers, dependence on interspecific interactions likely to be disrupted by stressor, and rarity), and Nicotra et al. (2015) identified three key domains of species' ecological adaptive capacity (life-history traits, genetic variation and evolvability, and phenotypic plasticity).

Importantly, the characterizations described above only reflect one facet of knowledge, namely scientific knowledge, which is typically decontextualized and may contrast with in situ, local, place-based values (Vincent et al. 2020). Efforts to bridge scientific and local knowledge systems may help coconstruct domains that are meaningful for the affected stakeholders and remain scientifically robust and transferable to other contexts (Reed 2008, Sterling et al. 2017).

In some cases, domains can include multiple elements that are deemed locally relevant. For example, various elements of education have been identified as being important for adaptive capacity of Pacific Island communities that go beyond the standard indicator of formal education. These include quality of education; role of local knowledge/language in formal education; local beliefs/values toward formal and informal education; diverse learning opportunities; access to and use of vocational training; and access to and use of technical and scientific information (Dacks et al. 2019). Various model structures linking exposure, 
Fig. 2. Conceptual diagram illustrating the three proposed nested layers for theoretically and contextually grounded vulnerability assessments: dimensions (inner circle), domains (middle circle), and indicators (outer circle). Examples of domains and indicators are modified from (Marshall et al. 2017, Cinner et al. 2018, Day et al. 2019) and describe the social vulnerability of resource-dependent communities to climate change.
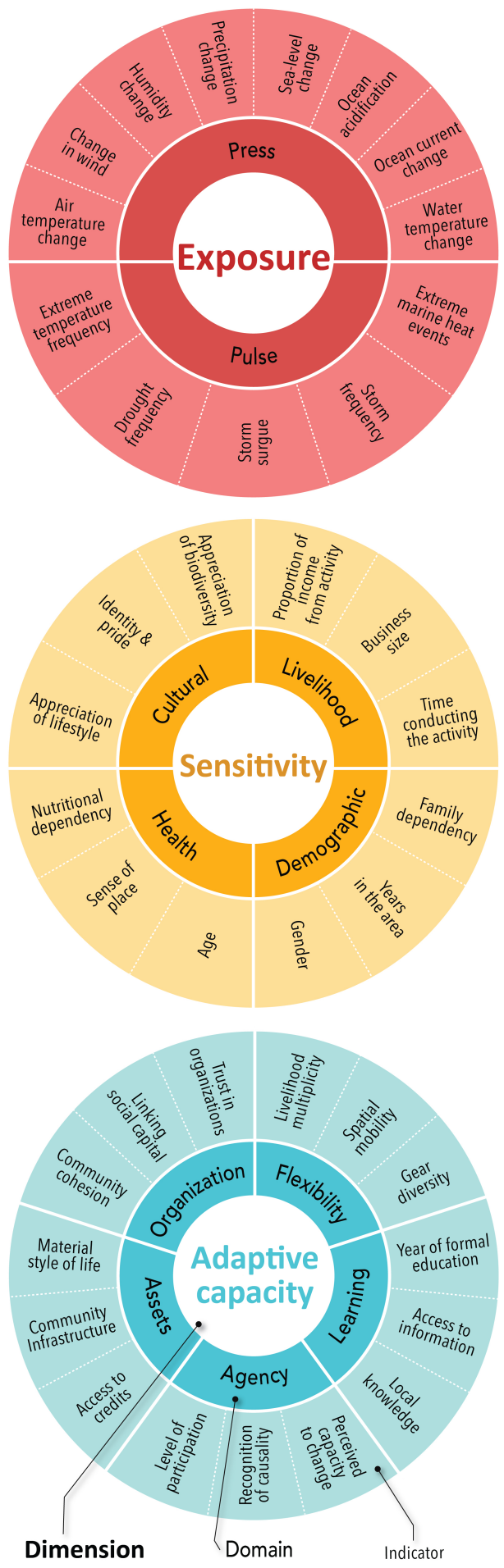

sensitivity, and adaptive capacity have been proposed in the literature to reflect the way the system was conceptualized initially (step 2). In its simplest form, a vulnerability assessment focuses on one single type of component (e.g., communities, countries, species, habitats, ecosystems) in relation to a single stressor (e.g., economic shock, population growth, tropical cyclone, climate change). In this case, exposure and sensitivity determine the potential impact, and vulnerability then results from the potential impact combined with (or tempered by) adaptive capacity (Fig 3a).

In more complex instances, social and ecological components may be considered as linked and interdependent, for example, through ecosystem services delivery (e.g., vulnerability of a social component to vulnerability of the ecological component), use (e.g., vulnerability of ecological component to use by a social component), or both. In such cases, social and ecological vulnerabilities are "coupled" and influence each other: the ecological vulnerability assessment is used as input data to the exposure of social vulnerability (Marshall et al. 2009, Cinner et al. 2013a), and social sensitivity potentially affects ecological exposure (Thiault et al. 2018a, b; Fig. 3b). Alternatively, an "integrated" assessment dove-tails both ecological and social indicators in a single assessment step to deliver results that identify the main sources of vulnerability and determine which actions will be the most effective (Abson et al. 2012, Johnson and Welch 2016, Johnson et al. 2016, Bell et al. 2018; Fig. 3c). Selecting between a "coupled" or "integrated" approach depends on the understanding of the linkages between social and biophysical systems (step 2). If the objective of the assessment is to examine the vulnerability of two or more components to the same stressor, dimensions are likely to be specific to each component (Fig. 3d), unless shared pathways and processes are involved across components. For instance, in their global assessment of the vulnerability of agriculture and fisheries (the components), Blanchard et al. (2017) and Thiault et al. (2019a) used sector-specific exposure (projected changes in sectoral productivity) and sensitivity (dependency on each sector), but adopted a generic view of adaptive capacity because they considered that their indicator (level of economic development) enabled a country to mobilize resources and adjust any type of food production sector to the potential impacts of climate change. Alternatively, an assessment of one component to two (or more) stressors (O'Brien and Leichenko 2000, Leichenko and O'Brien 2002, Bennett et al. 2015, Thiault et al. 2019b) may require a parallel assessment where some domains and indicators are generic to all stressors while others are stressor-specific (Fig. $3 \mathrm{e})$. This approach is analogous to the cumulative impact approach (Halpern and Fujita 2013), which applies a "vulnerability weight" (sensitivity and adaptive capacity sensu Table 1) that translates the intensity of each stressor (exposure) into its predicted impact. Because model structure determines, to some extent, the degree to which indicators can or should be aggregated (step 9) and interpreted (step 10), one needs to be thoughtful about the choices made in this step.

Step 5: Indicators

Indicators are characteristics or processes that can be measured or estimated to track the state or trend of a particular domain. Indicators, more so than dimensions or domains, can be customized (Box 1) to each specific context, availability of 
Fig. 3. Examples of possible structures for the vulnerability assessments, depending on how the system was conceptualized. (a) Default Intergovernmental Panel on Climate Change vulnerability framework. (b) Coupled social-ecological vulnerability framework where ecological vulnerability shapes exposure (i.e., degradation of the ecological system affects the social system), and social sensitivity and adaptive capacity may shape ecological exposure (e.g., high dependence on the ecological system for production leads to high exposure; dashed arrow). (c) Integrated social-ecological vulnerability combining social and ecological indicators within each vulnerability dimension. (d) Vulnerability of two components (e.g., agriculture and fishing sectors) to a single stressor (e.g., climate change). (e) Vulnerability of a single component (e.g., resource-dependent communities) to two stressors (e.g., climate change and markets).

\section{a - Vulnerability of one component to one stressor}

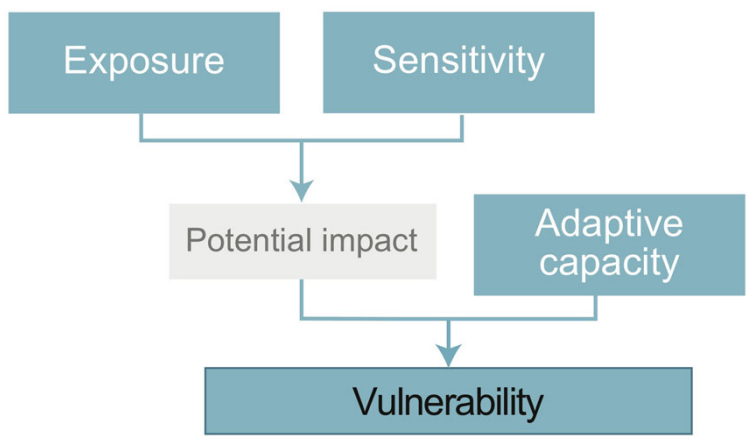

\section{c - Integrated social-ecological vulnerability}

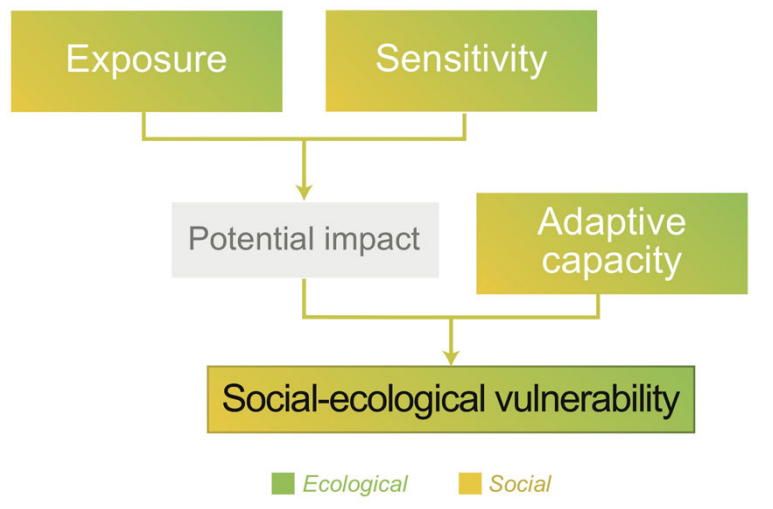

\section{d - Vulnerability of two components to one stressor}

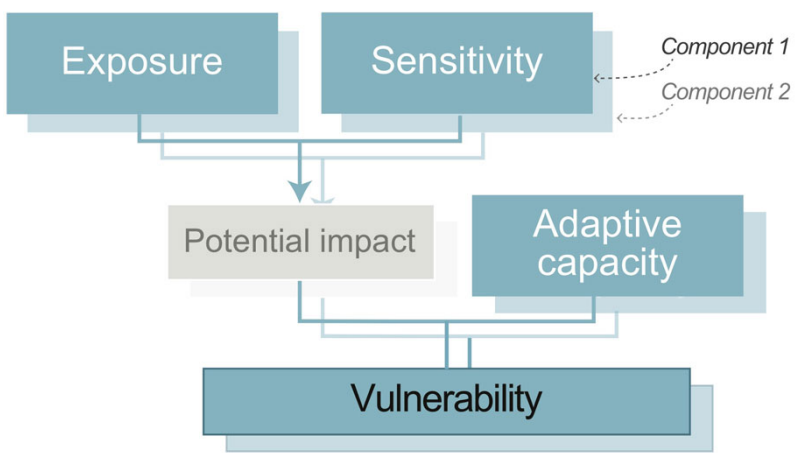

\section{b - Coupled social-ecological vulnerability}

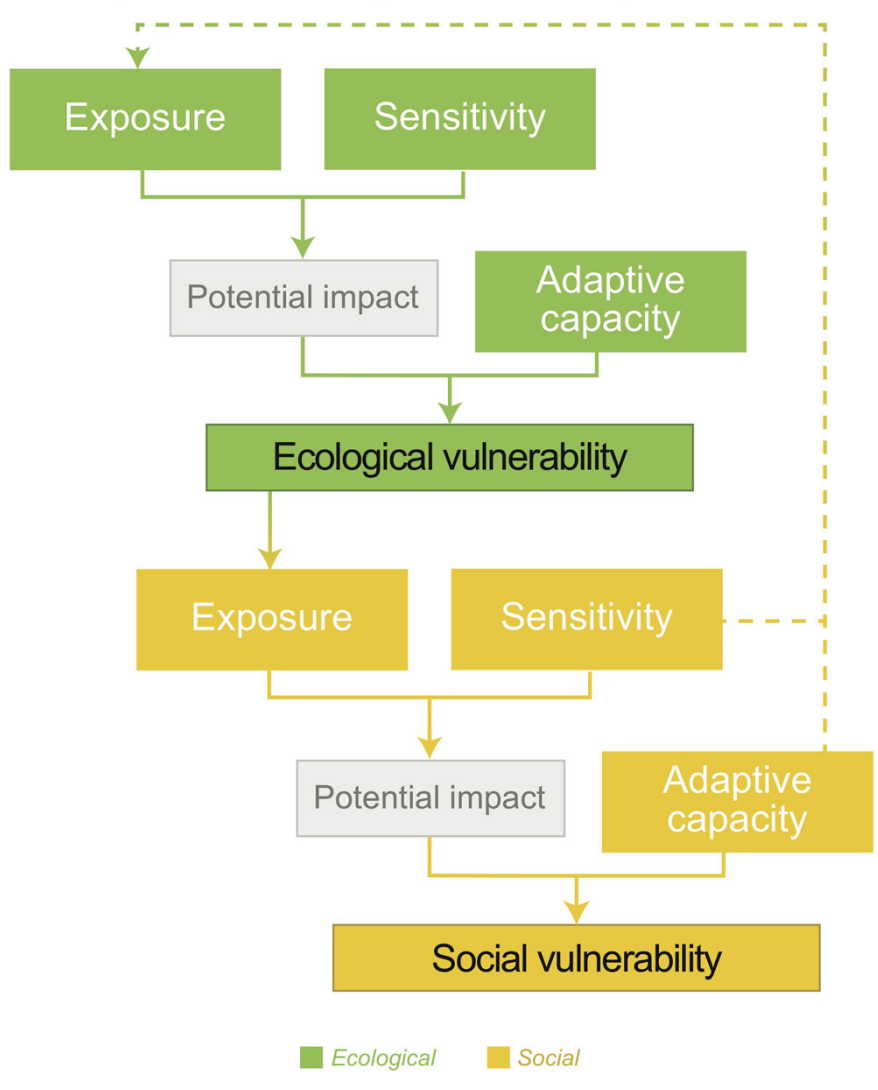

\section{e - Vulnerability of one component to two stressors}

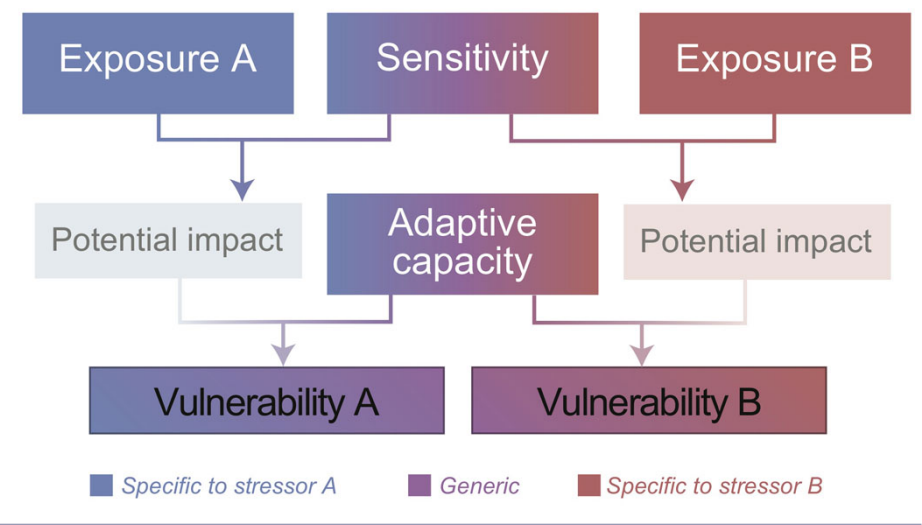


information, and the overall resources available. The best indicators are those that are specific, measurable, attainable, relevant, and time-bound (SMART).

Analysts use indicators as quantifiable characterization of system components and attributes. In doing so, they place value on what they believe to be important representations of exposure, sensitivity, and adaptive capacity and their underlying domains.

Any evaluation of vulnerability based on indicators will always comprise a subset of all possible sources of vulnerability and so will capture only a fraction of "true" vulnerability (Brenkert and Malone 2005). For example, some cultural values and knowledge are characteristically nonspatial (Ban et al. 2013) and may be impractical to incorporate in a spatial vulnerability model. Bias toward easily quantifiable indicators can miss critical elements driving system vulnerability, whereas indicators that are not relevant to local viewpoints, aspirations, and cultural settings can misdirect the assessment outputs and result in the implementation of programs that do not fit local contexts (Sterling et al. 2017). It is therefore critical to define what the subset of indicators represents and what it omits. Cocreation of indicators with the people and stakeholders invested in and affected by the process is critical so that they are both context grounded and also reflect local worldviews (Tengö et al. 2014, Lemos et al. 2018, Wyborn et al. 2019) and engage with approaches that build upon local cultural perspectives, values, knowledge, and needs (Sterling et al. 2017). For example, resource-dependent communities, which are at the frontline of environmental change, have experiences that can provide local expertise on suitable indicators (McMillen et al. 2014). However, it is important to note that this type of coproduction of indicators can create trade-offs with generalizability, as the indicators developed may lack meaning and applicability in other locations.

Because individual indicators generally do not perfectly characterize each vulnerability domain, and because indicators are subject to measurement uncertainty (step 9), it is desirable to consider several indicators concurrently for each domain. Dimensionality can then be reduced, for example, using correlation analyses (step 8). Similarly, it may be important at this stage to reflect on the desired level of data integration (step 8). Indicators also need to reflect what can be addressed by management interventions in order to avoid a mismatch between what is assessed and what is addressed (step 10).

\section{Operationalization (Phase C)}

Once the assessment design is established, methodological issues need to be considered. This phase includes reflecting on how data are collected and analyzed, and estimating underlying uncertainties so that the outputs can be adequately represented and interpreted.

\section{Step 6: Data collection}

How the data are collected, why, and by whom are all important considerations because the data included in the vulnerability assessment will inform the outcomes, relevance, applicability, and use. It is therefore important to consider the most appropriate method and methodology for each indicator, and how this may influence the outcomes of the vulnerability assessment. Because each vulnerability assessment is context-specific, the most appropriate data may again vary depending on scope, circumstances, and resource availability (steps 1-3).
Possible data sources include data from primary research (ecological surveys, interviews, perceptions, model projections), secondary data sets (official databases, censuses, spatial data), and grey literature (Kittinger et al. 2014). It is of great value to incorporate local actors, decision makers, and other stakeholders in the research. To achieve this, existing empirical data could be considered along with information derived from expert elicitation, local surveys, participatory mapping, workshops, and focus groups (Huynh and Stringer 2018, Cochrane et al. 2019). By contrast with the above "objective" approaches that are independent of the subject's judgment, a "subjective" analysis relying on people's selfassessments of their own exposure, sensitivity, or adaptive capacity may be employed (Jones 2019).

Importantly, the vulnerability assessment and associated data collection must be ethical, and ethics applications should be sought wherever is necessary and appropriate. Ibbett and Brittain (2020) recently found that nearly half of the conservation journal articles that should have included ethics information did not, which means important ethical safeguards were not in place for human participants or collaborators in this research. Ethics will be an especially important consideration for vulnerability assessments because these assessments are typically carried out in areas where people may already be vulnerable.

\section{Step 7: Standardization}

Unless using an inductive approach (step 8), indicators generally have to be standardized through transformation and rescaling so that indicators of different units (e.g., number of person/job in households, degrees heating from climate change, contribution of an activity to livelihood) and scales (e.g., individual vs. community vs. country level) can be integrated (step 8). Decisions about if and how to standardize data can have important consequences on the outcomes of vulnerability assessments and require careful consideration.

Data transformation deals with handling skewness and distribution. Although there is no single right answer for how best to transform data, there is reasonable justification for preserving some or all of the skew when making decisions about deciding data transformation because the original variability generally represents real differences, and usually has relevance for understanding how vulnerability differs among components. Transformation may nevertheless be necessary to improve the interpretability of data or eliminate the effects of certain outliers that otherwise would compress the variation. Common data transformation methods include Min-Max normalization and $\mathrm{Z}$ score normalization or, when the distribution is skewed toward one side, root-, cube, and log-transformation. Winsorization can also be applied when extreme values are present. This transformation sets outliers to a specified percentile of the data and has been applied in vulnerability assessments (e.g., Ekstrom et al. 2015). With knowledge of threshold responses in systems, outliers value could be Winsorized to the tipping point value, but these are currently unknown assumptions in the majority of cases, especially for social components, and in turn would require more assumptions. Fuzzy logic techniques can also be employed to standardize and synthesize indicators, especially in cases with complex response behavior patterns (Singh and Nair 2014, Jones and Cheung 2018).

Rescaling involves adjusting values measured on different scales to a notionally common scale, say $0-100$. In certain cases, 
indicators may already be scaled in this manner and can be used as is. In other cases, the indicator can be defined as a percentage, e.g., contribution of fishing to household income, proportion of climate-sensitive species, and can be readily converted to a $0-100$ scale. Other indicators may have a finite range of possible values, e.g., level of trust on a Likert scale or Shannon diversity, and could be scaled by simply applying a constant multiplicative factor. Some, more challenging indicators do not have a bounded range of possible values, e.g., household size or species biomass. In such cases, the lowest and highest values are generally used to define the bounds and rescale the other values proportionately, assuming that they represent the true range of all possible values. Whatever the decision about selecting these methods, it is important to be explicit and transparent about the decision. For semiquantitative assessments where secondary data or grey literature are used, scores are generally assigned for each indicator using criteria on a 3-point (or 5-point Likert) scale and the scores for each indicator are standardized and normalized to account for score variability.

\section{Step 8: Integration}

Once standardized, it can be useful to combine indicators to provide a composite measure of vulnerability. When integrating, care should be taken to ensure complementarity of indicators, their relative values, which standardization provides, and their relative importance to the system analyzed.

There are many ways that data can be integrated in a vulnerability assessment (de Sherbinin et al. 2019). Depending on the level of analysis required (step 10) and the structure of the conceptual vulnerability model (step 4), indicators may be aggregated at the domain, dimension, or overall vulnerability level (Box 1 and Fig. 3). This requires accounting for the relative importance of indicators (weights) and the way they interact to reflect the desired level of analysis. Aggregation and weighting methods are strong determinants of the outcomes of the vulnerability assessment (Monnereau et al. 2017) and this is why it is important to reflect on the appropriate approach.

There are three broad categories of weighting approaches. The first one relies on empirical weights derived from statistical models, e.g., regressions, tree-based, or structural equation models, to explain vulnerability outcomes, i.e., a measured change in a component's attribute, as a function of indicators describing exposure, sensitivity, and adaptive capacity (Eakin and Bojórquez-Tapia 2008, Hinkel 2011, Morel et al. 2019). The rationale behind this "inductive approach" is that the means by which indicators determine vulnerability in one context can be translated to predict vulnerability in other similar contexts. Although results depend strongly on the inputs and available data being modeled, inductive approaches remain useful to refine theory and assess which particular indicators and interactions are more closely associated with vulnerability in a given context. Although very powerful, these kinds of approaches have rarely been applied in practice so far because they typically require the model to be built prior to the vulnerability assessment and rely on large amounts of data.

Another less robust but more operational method when empirical data are lacking builds on available theory and knowledge to identify how indicators combine to form vulnerability. Because such information is generally qualitative by nature, "deductive arguments" rely on metrics such as the number of scientific papers attributing a causal effect of an indicator on an attribute to estimate the "amount of scientific evidence," and thus the weight, supporting a given indicator or domain (Cinner et al. 2013a). Alternatively, weights can be assigned by a pool of experts, i.e., academics, decision makers, managers, or stakeholders, either directly, or (preferably) indirectly using ranks to elicit scores through mathematical formulas and multiple-criteria decision analysis, e.g., analytic hierarchy process, measuring attractiveness by a categorical-based evaluation technique (see, for example, McClanahan et al. 2008). Of course, expert judgements are not immune from potential biases (differences in experts' values, risk tolerance, and other subjective influences), but these can be minimized using a large number of experts to survey if the expert pool is large enough. They also have the added advantage of improving participation.

Third, approaches that cannot rely on inductive or deductive arguments have estimated weights based on the variability of the data for a given indicator, e.g., principal component analysis (Abson et al. 2012). Such a data-driven "descriptive approach" is based on the structure (co-occurrence and correlation) of the indicators. Highly correlated indicators, e.g., wealth and education, or functional and taxonomic diversity, will tend to group together, and different principal components could be used to evaluate domains. Another type of deductive approach includes the use of equal weightings schemes (Tonmoy et al. 2014) under the assumption that all indicators contribute equally to a particular domain nested in a particular dimension. Choosing between a deductive and a descriptive approach is a decision based on the available data and whether it is known that some indicators are more important than others in influencing vulnerability negatively or positively. Although it is likely that the influence of indicators is not equal, a decision should be made to treat them equally if the value and interactions among indicators are not well understood (Allison et al. 2009).

Despite being a defining feature of SES (Parrott and Meyer 2012) that has been highlighted in the vulnerability literature (Luers 2005), nonlinear relationships are difficult to incorporate in practice because of the lack of information on how indicators, domains, and dimensions of vulnerability generally interact to determine vulnerability. This is particularly true for deductive and descriptive approaches, which only provide weight estimates. Without clear evidence to include complex interactions, additive and multiplicative vulnerability remain default models. But both models require more assumptions. Additive models assume that the indicators are perfect substitutes, meaning that low value in one is compensated by high value in another one. Multiplicative models imply that vulnerability, dimensions, or domains are limited by the lowest variable of the underlying determinants (but see Tol and Yohe 2007 for an empirical disproval of this assumption in a hazard/risk context). Other approaches based on ranks (Parravicini et al. 2014) or network-based methods (Debortoli et al. 2018) have also been used in order to minimize the effect of data transformation on the final output.

\section{Step 9: Uncertainties}

Uncertainty is a ubiquitous problem in vulnerability assessments, yet, few studies have explicitly engaged with it (Tonmoy et al. 2014). Uncertainty can emanate from four main sources. First, 
some processes generating vulnerability may not be known or quantifiable. Second, while individual indicators hold a relationship to a process generating vulnerability, the nature of this relationship is often undetermined (step 8). Third, random (i.e., caused by natural fluctuations of indicators) and systematic errors (i.e., caused by the measurement method) can generate a high level of imprecision, especially if they are averaged over spatial or temporal scales and/or projected into the future. Fourth, indicators and the weights attached to them are sometimes evaluated by interviewing stakeholders or experts and the process inevitably carries a level of subjectivity, as well as possible variances between the opinions of different informants.

Various methods have been used to capture these different sources of uncertainty. The use of multiple indicators to depict individual domains (steps 4-5), for instance, is a simple method to reduce random and measurement errors. Fuzzy-set theory has been used to incorporate uncertainty stemming from vague definitions and lack of knowledge about vulnerability and its dimensions (Eakin and Bojórquez-Tapia 2008, Eierdanz et al. 2008, Jones and Cheung 2018). Common multiple-criteria decision analysis methods often provide an estimation of judgement consistency, and can be used to adjust scores during expert elicitation exercises aiming at estimating indicator weights (Eakin and Bojórquez-Tapia 2008, McClanahan et al. 2008, Thiault et al. 2018a). In addition, computational experiments such as Monte Carlo simulations help investigate the range of possible vulnerability outcomes by modeling vulnerability under various combinations of data sources, transformation, aggregation, and/or weightings methods, thus enabling to distinguish robust from less reliable modeling results (Thiault et al. 2018a, 2019b, Bourgoin et al. 2020). Sensitivity analyses enable estimates of the overall influence of such factors and provide important knowledge for reviewing their reliability and potentially directing monitoring effort to increase robustness of the assessments. Issues of uncertainty are not confined to vulnerability assessments, and lessons on how to deal with uncertainties can be learned from more mature strains of applied research such as cumulative impact assessments (Halpern and Fujita 2013, Stock and Micheli 2016, Stelzenmüller et al. 2018).

Assessing uncertainties is a valuable component of vulnerability assessments. Not only does an integrated measure of uncertainty in the final result inform the measure of confidence in applying the outcomes, it can also inform potential revision to how indicators may have been selected (step 5), collected (step 6), or integrated (step 8). Perhaps of greatest value, quantified (including categorized) uncertainty can identify opportunities for future efforts to reduce the determined uncertainty, e.g., through additional research efforts.

When vulnerability is assessed in the context of climate change, the exposure dimension is often represented by general circulation models (GCMs) derived projections. Because climate forecasts are based on future scenarios of greenhouse gas (GHG) emissions, it is essential that climate change vulnerability assessments explicitly state and describe the assumptions pertaining to GHG emission, i.e., climate change scenarios, considered in the assessment (IPCC 2014). Understanding the assumptions underpinning each of the emission scenarios is also necessary for comparing and matching future climate predictions across different generations of IPCC climate change scenarios (i.e., SRES, AR5, AR6) and allows the use of data from a diverse set of models and scenarios.

\section{Implementation (Phase D)}

The results of a vulnerability assessment are not an endpoint, but a source of information to incorporate into decision making and planning. This phase is about moving from assessment results to real-world application. The success of this phase determines the extent to which vulnerability will be practically managed and the concept made useful.

\section{Step 10: Interpretation}

Interpreting the outputs of vulnerability assessments is essential for decision making. This step entails reflecting on how vulnerability can be portrayed in two, complementary ways: aggregated or disaggregated. First, assessments that describe vulnerability at the highest aggregation level produce a vulnerability score and/or ranking. This information can in turn help decision makers select targets and set priorities, e.g., protecting the 15 most vulnerable species, investing in capacity building for the $10 \%$ most vulnerable areas assessed, or spreading effort across the range of vulnerability scores. Aggregated vulnerability portrayals are especially suited in a spatial context, where vulnerability hotspots can be prioritized or discarded, depending on the overall strategy (Parravicini et al. 2014, Smith et al. 2016, Thiault et al. 2018a, de Sherbinin et al. 2019). This type of information can potentially be incorporated within a framework for systematic prioritization, for instance via Marxan or prioritizer. Fully aggregated vulnerability outputs are also useful for temporal comparisons, where the vulnerability of a system is expected to change over time following a particular event or intervention (Thiault et al. 2018b) or over multiple time periods (Naylor et al. 2020).

Although aggregated assessments of vulnerability are useful, they can lack the specific recommendations needed by decision makers to understand and effectively manage SES because of the lack of resolution to understand the exact drivers of the overall score. The second, disaggregated representation typically considers the multiple dimensions of vulnerability (Sietz et al. 2011, Foden et al. 2013, Kok et al. 2016). By looking at the interactions between exposure, sensitivity, and adaptive capacity, leverage points can be identified (Fischer and Riechers 2019) and option space for management and policy explored. Indeed, if low vulnerability is the fundamental objective, then it can be achieved via actions to reduce exposure, decrease sensitivity, build adaptive capacity, or a combination of those, depending on the main sources of vulnerability. This approach helps ensure that strategies actually address the causes of vulnerability and do not just target the symptoms of it.

An array of strategies to address each dimension contributing to vulnerability has been identified. These are generally derived from the applied research literature and "translated" in the language of vulnerability (Thiault et al. 2020). For example, in their vulnerability assessment of fishing communities to the impacts of climate change, Cinner et al. (2012) have proposed interventions focusing on strengthening community groups and investing in strong local institutions to build social adaptive capacity, both of which are directly derived from Ostrom's and colleagues' work on commons and fisheries applications (Ostrom 2009, Basurto et al. 2013). Other recommendations based on this assessment include the development of social safety nets, adaptive management approaches or poverty reduction, and diversifying livelihoods, which are core principles of the sustainable livelihood 
approach (Allison and Ellis 2001, Allison and Horemans 2006). Many examples of vulnerability assessments in the ecological realm have emerged over the recent years and identify avenues for management and policy using the same rationale (Johnson and Marshall 2007, Foden et al. 2013, Parravicini et al. 2014, Anthony et al. 2015, Bell and Taylor 2015, Okey et al. 2015, Johnson and Welch 2016, Johnson et al. 2016), illustrating the ability of this framework to foster multidisciplinary assessments that inform targeted policy and management.

Of course, aggregated and disaggregated approaches are not mutually exclusive and can be taken sequentially, thus providing a richer understanding of management priorities and potential strategies. Cluster analyses that group a set of components according to the similarity of their indicators or domains are an example of hybrid approach to identify both management priorities (high vulnerable clusters) and options (cluster-specific sources of vulnerability requiring cluster-specific interventions; Sietz et al. 2011, 2017, Foden et al. 2013).

Each intervention should be evaluated against other broader social, economic, and cultural considerations, as well as the opportunity context defined in step 1. For example, the "sweet spot" for management in terms of an ideal intervention can be to target a component assessed as highly vulnerable where importance (value) and amenability to management (cost effectiveness) are also high (Johnson et al. 2016). Outside this sweet spot, there will be trade-offs among the three and managers can select the trade-offs that best align with the management objectives, stakeholder values, and budget.

Finally, issues important to consider when strategizing include how to create the most powerful combination of actions, and how different actions should be sequenced in time and organized across scales. For example, for a new harvesting practice to become adopted, practitioners may need to first build awareness around the negative effects of the old practice, and to change current incentive structures before promoting the new one. As in previous steps, it is important to document the evidence and assumptions regarding how each selected action might reduce vulnerability, and that all the stakeholders affected by the process are involved when identifying and short-listing actions.

\section{Step 11: Communication}

Once the outputs are obtained, care should be given to the way the results are communicated. Failure to communicate effectively can lead the target audience, which may include decision makers, target beneficiaries, donors, the academic community, or the general public, to absorb a fragment of the assessment outputs and exaggerate its value, or selectively pursue convenient truths (National Academies of Sciences, Engineering, and Medicine 2017).

How best to package and communicate the assessment may differ depending on the audiences. Serving diverse audiences thus requires people with the ability to understand recipients, craft communications, disseminate messages, and mind cultural sensitivities (Fischhoff 2013). Science communication experts can help in developing a communications plan with key messages tailored to each audience and vehicles for delivering those key messages given resource availability. Effective communication of vulnerability assessments affords people a shared understanding of the facts and can help mobilize action and engender widespread support.

Importantly, the vulnerability terminology has been criticized for being disempowering to local communities and labeling local communities as victims (Cameron 2012). Responses to these critiques note that vulnerability assessments seek to draw attention to the contexts that shape how a stressor is experienced and likely to be responded to by the system, and that terms including "vulnerability" and "sensitivity" should be used in academic and government writing but not communication with communities (Table 2). For communication to the wider public, practitioners should instead seek to put emphasis on more positively valenced concepts such as resilience and adaptive capacity, and be consistent with local terminology and ontologies (Fawcett et al. 2017).

As in any risk or cumulative impact assessment (Stelzenmüller et al. 2018), being transparent about uncertainty levels (step 9) is of primary importance when communicating vulnerability results. One should also pay attention to clearly articulate terms and avoid undefined acronyms or obscure technical jargon for public communication. Equally important is to weigh the risks of inaction in an analysis of options and the consideration of uncertainty.

For effective communication, practitioners should employ available media and visual aids, e.g., graphs, tables, maps, and figures, for dissemination. Use of color in graphics to indicate relative vulnerability of the component assessed and error bars to indicate the limits of uncertainty can be powerful means of communication (Dubois et al. 2011). Media such as brief reports, infographics, and summary tables can quickly convey complexities that are hard to explain in other ways. Recently, social media has become increasingly useful for disseminating results to broad audiences. For example, Twitter, Facebook, and Instagram posts that include striking images, graphs, and videos can direct audiences toward more in-depth reports, briefing notes, and media reports about vulnerability assessment results, while enabling the popularization of ideas that might otherwise be overlooked in decision-making processes.

\section{Step 12: Learning}

Learning is an ongoing endeavor throughout a vulnerability assessment. The scoping, design, and operationalization phases are intended to stimulate learning, as are the interpretation and communication steps. Two main ways that learning often evolves is through (1) deep systems understanding, which may take decades to acquire; and (2) measurement of adaptation following a system shock (Berkes and Turner 2006). The use of vulnerability assessments potentially represents a third way of learning that takes a diagnostic approach, which can build on elements of deep systems understanding and how similar systems have responded to stressors in the past, but does not necessarily rely on long-term investment in a place and/or observing responses through a major shock.

However, true learning and knowledge sharing cannot occur unless analyses are effectively communicated, shared, and used to inform practice through adaptive management (steps 10-11). Yet, the transfer of data and knowledge remains a neglected key step in vulnerability assessments. Transparent and replicable 
assessments give researchers, decision makers, and stakeholders confidence in the assessment and help improve SES understanding as a whole. Failure to transparently share information precludes a full understanding of what has been done for people not directly involved in the process. Although decisions are rarely derived solely on the basis of vulnerability assessment, the process and products of the assessments often provide the foundations for discussions in arenas where multiple knowledge sources compete in supporting a decision (Claudet et al. 2020). In such arenas, the uptake of vulnerability assessments is facilitated when all the steps are revealed and where all the decisions that have been taken are documented.

Replicability is necessary to evaluate the system's responses to environmental change, assess how management interventions affect vulnerability, or account for new relevant data as it becomes available. Replicated assessments can also indicate if management priorities, resource allocations, and applied interventions have been fit and appropriate for reducing vulnerability. Guidance now exists on how to make science more open and replicable (Lowndes et al. 2017). Developing a repository of vulnerability assessments, where all the above choices are explicitly documented, as it exists for other fields (e.g., EcoBase for Ecopath with Ecosim food web models [Christensen et al. 2004] and systematic planning [ÁlvarezRomero et al. 2018]) would help in respect to transparency and replicability.

Ensuring transparency and replicability also provides the foundations for reflective practice, that is, an approach that questions, tests, and refines knowledge and assumptions based on previous outcomes is recommended. Learning during the process may indeed necessitate revisiting a previous phase, for example, to change the composition of the core team (step 1), to select different indicators (step 5), or to come up with alternative strategies for reducing vulnerability (step 10).

\section{FUTURE RESEARCH AVENUES}

We identified future avenues for research and application to make vulnerability assessments more robust and useful. The ideas below are not the only way forward for improving vulnerability assessments (Eakin and Luers 2006), but they represent potential pathways for evaluating vulnerability in a way that is cognizant of the contemporary challenges facing SES and more in line with the present discourse on environmental policy.

\section{Biocultural approaches}

When conducted in an ethical way, bringing together multiple ways of knowing through biocultural approaches can lead to new insights and innovations for maintaining and enhancing system resilience and thus reducing vulnerability. Biocultural approaches are those that are initiated from place-based cultural perspectives and worldviews and recognize the direct connections between ecological state and human well-being (Sterling et al. 2017).

Biocultural approaches explicitly differ from some knowledge coproduction approaches to understanding SES in that the starting point must be from a "culturally grounded understanding of what factors drive a system" (Sterling et al. 2017:1800). In the context of vulnerability assessments, particularly those that engage Indigenous peoples and local communities, this is likely to require adapting system literacy during systems exploration (step 2) to make the language of vulnerability mutually comprehensible and inclusive when engaging with "multiple domains and types of knowledges, with differing logics and epistemologies" (Agrawal 1995:433). Although some guidance exists on how to work with multiple-knowledge systems in other sectors (Cochran et al. 2008, Kutzand Tomaselli 2019), its practice has not been widely applied in vulnerability assessments and demands critical focus.

Critical components of biocultural approaches include acknowledging that there are multiple stakeholders who all have differing objectives; recognizing the importance of intergenerational planning and institutions for long-term adaptive governance; recognizing that culture is dynamic; tailoring interventions to the social-ecological context; drawing on diverse and nested institutional frameworks; prioritizing the importance of partnerships and relationship building for achieving outcomes; incorporating the rights and responsibilities of all parties; and incorporating different worldviews and knowledge systems into planning (Gavin et al. 2015). Implementing these approaches through systems exploration and review (steps 2-3), indicator development (step 5), interpretation (step 6), and communication (step 11) will result in a framework that is culturally grounded, better able to capture social-ecological interdependencies, and identifies leverage points for intervention that will genuinely reduce system vulnerability and improve human well-being.

Given that biocultural approaches typically demand a greater amount of stakeholder engagement, which can be costly, there is a need to identify the most effective ways to ethically engage with different knowledge systems, including through the development of culturally grounded indicators (step 5), in order to optimize appropriate characterization and reduction of system vulnerability. The stakes are high: mischaracterization of a system through failure to understand local conditions and interactions can lead to management interventions that do not work or are maladaptive and increase vulnerability (e.g., Aselu 2015).

\section{Trade-offs and maladaptation}

A critical gap in vulnerability practice is insufficient consideration of the potential unintended or perverse side-effects that interventions seeking to reduce vulnerability may have (Schipper 2020). It is often assumed that reducing vulnerability through targeted actions addressing the source(s) of vulnerability, e.g., enhancing adaptive capacity or reducing sensitivity, will benefit the SES as a whole. Yet, the relationships between the various components of a SES are complex, unlikely to be fully captured by a vulnerability assessment, and therefore feedbacks and linkages may lead to unwanted outcomes at the SES level.

One of the key aspects of social-ecological vulnerability may be the potential for high social adaptive capacity (generally considered desirable) to enable exploitation and degradation of an ecological component (generally considered undesirable; Cinner et al. 2011, Bird and Yuen 2020). This phenomenon has been termed amplifying adaptive capacity because of the propensity for adaptive capacity to amplify environmental change (Cinner et al. 2011). However, we know little about how to avoid amplifying adaptive capacity and how to foster adaptive capacity associated with responses likely to reduce ecological degradation (dampening adaptive capacity). Unrecognized trade-offs inherent in vulnerability-based management may also occur across vulnerability domains and across spatial and temporal scales 
(Cinner et al. 2018). Other forms of trade-offs occur when stressor-specific capacity building programs inadvertently increase vulnerability to other stressors. This may occur, for instance, when high adaptive capacity exposes people to new stressors, increases their sensitivity to these new stressors, or crowds-out the means available for other stressor-specific adaptation (Belliveau et al. 2006, McDowell and Hess 2012, Bacon et al. 2017, Finkbeiner et al. 2018).

Maladaptation can occur when, for example, capacity building, e.g., through improved infrastructure or insurance, leads people to be overly reliant on these safety nets and become complacent or fail to perceive the need to invest in risk planning (Næss et al. 2005, Eakin and Bojórquez-Tapia 2008, Saldaña-Zorrilla 2008, Adger and Barnett 2009, Lemos et al. 2013, Barnett et al. 2015, Pomeroy et al. 2017). Without the need to weigh the risks, people may no longer engage with their previous networks, thereby reducing the overall social capital and risk awareness necessary to respond to and mitigate the exposure (Müller et al. 2017).

Despite the numerous real-world examples of trade-offs and maladaptation, they continue to happen. Anticipating these with certainty is difficult, but considerations of key factors, such as local social-ecological contexts, interconnectedness of system components, and existing risk coping strategies can help in this process (Schipper 2020). Furthermore, more research is needed to understand the likely positive or negative outcomes that interventions might have across dimensions, domains, components, and stressors, and reduce uncertainty in vulnerability-based decisions (Heltberg et al. 2009).

\section{Vulnerability to nonclimatic stressors}

So far, most applications of the vulnerability concept have focused on the socioeconomic impacts caused by hazard- and climaterelated stressors, and most knowledge on vulnerability relates to these schools of thought. However, SES are exposed and potentially vulnerable to a broad range of socioeconomic and biophysical stressors beyond climate and the subsequent environmental change (Bennett et al. 2016). As a consequence, vulnerability has gained traction in other areas, with applications ranging from social vulnerability to management (Chen et al. 2014, Chen and Lopez-Carr 2015, Tilley et al. 2018), socioeconomic changes (O'Brien and Leichenko 2000, O'Brien et al. 2004, Belliveau et al. 2006, Thompson et al. 2016), poaching (Thiault et al. 2019b), fire (Aretano et al. 2015), and other human uses of ecosystems (Jones and Cheung 2018, Thiault et al. 2018a, Bourgoin et al. 2020). However, such assessments tend to lack theoretical or empirical underpinnings, and are consequently undertaken without a good understanding of the determinants and processes affecting vulnerability in that particular context.

One possibility to improve the robustness and relevance of the vulnerability concept outside of its original field may be to draw on other, linked strains of research more explicitly. Ecological vulnerability assessments, for instance, are largely based on work from the resilience and ecotoxicology literatures (Ippolito et al. 2010, Mumby et al. 2014, Beroya-Eitner 2016), which use similar languages and concepts, e.g., sensitivity/resistance or adaptation/ recovery, and enable inference from empirical evidence. With regard to social vulnerability in a management and natural resource management context, lessons can be learned from diagnostic and archetype approaches when looked at through the lens of vulnerability (Oberlack et al. 2016, Sietz et al. 2017, Vidal
Merino et al. 2019). For instance, Ostrom's SES framework (Ostrom 2009) can serve as a knowledge base for identifying the key attributes that foster or hinder SES sustainability and relevant interventions to reduce vulnerability (Gurney et al. 2019).

When it is not possible to link vulnerability to findings from other fields, inductive approaches (step 8) could be employed. Beforeafter/control-impact types of assessments can be applied to test, for example, the sources of adaptive capacity that fishers draw upon when a new marine reserve is implemented in their fishing grounds (vulnerability to management), or how exposure to new market conditions is experienced by resource-dependent communities depending on their levels of sensitivity and adaptive capacity. Although application of such powerful approaches to nonclimatic stressors remain relatively rare to date, there is much scope for progress given the increasing availability of long-term monitoring data and the growing capacity of statistical models at handling complex processes.

\section{CONCLUSIONS}

The structure that is presented here addresses many of the shortcomings of past approaches (Table 2), incorporating the best available science to define an approach to vulnerability assessments that is both more readily applicable and more robust. The intention is for this work to encourage practitioners to apply the best possible practices and stimulate much needed discussion and experimentation. With careful consideration of the issues raised here, vulnerability assessments can be built on stronger science foundations while also being more widely used, thus giving them the potential to substantively advance decision making in an increasingly challenging setting. The structure presented in this paper represents a set of steps that can be used to implement a vulnerability assessment. Applying best practice in all of the steps may not always be possible given available resources, accessibility to data sources, and the planning and effort required. Nevertheless, increased awareness of the issues covered here will help to prevent inappropriate conclusions from being drawn from vulnerability studies and help practitioners make the most of available information and insights. Improving the reliability of vulnerability assessments is not a small challenge, but a worthwhile one, given their great potential to provide balanced insights into management in a time when practical solutions to navigate new sustainability problems are needed.

\section{Responses to this article can be read online at: https://www.ecologyandsociety.org/issues/responses. php/12167}

\section{Acknowledgments:}

We thank LabEx CORAIL, Agence Nationale de la Recherche (ANR-14-CE03-0001-01), Fondation de France, Ministère de la Transition Écologique et Solidaire and the Foundation for Research on Biodiversity (ACID REEFS) for financial support.

\section{Data Availability:}

Datalcode sharing is not applicable to this article as no new datal code were created or analyzed in this study. 


\section{LITERATURE CITED}

Abson, D. J., A. J. Dougill, and L. C. Stringer. 2012. Using principal component analysis for information-rich socioecological vulnerability mapping in Southern Africa. Applied Geography 35(1-2):515-524. https://doi.org/10.1016/j.apgeog.2012.08.004

Adger, W. N. 2006. Vulnerability. Global Environmental Change 16(3):268-281. https://doi.org/10.1016/j.gloenvcha.2006.02.006

Adger, W. N., and J. Barnett. 2009. Four reasons for concern about adaptation to climate change. Environment and Planning A: Economy and Space 41(12):2800-2805. https://doi.org/10.1068/ $\underline{\mathrm{a} 42244}$

Adger, W. N., H. Eakin, and A. Winkels. 2009. Nested and teleconnected vulnerabilities to environmental change. Frontiers in Ecology and the Environment 7(3):150-157. https://doi. org/10.1890/070148

Agrawal, A. 1995. Dismantling the divide between indigenous and scientific knowledge. Development and Change 26(3):413-439. https://doi.org/10.1111/j.1467-7660.1995.tb00560.x

Allison, E. H., and F. Ellis. 2001. The livelihoods approach and management of small-scale fisheries. Marine Policy 25 (5):377-388. https://doi.org/10.1016/S0308-597X(01)00023-9

Allison, E. H., and B. Horemans. 2006. Putting the principles of the sustainable livelihoods approach into fisheries development policy and practice. Marine Policy 30(6):757-766. https://doi. org/10.1016/j.marpol.2006.02.001

Allison, E. H., A. L. Perry, M. C. Badjeck, W. N. Adger, K. Brown, D. Conway, A. S. Halls, G. M. Pilling, J. D. Reynolds, N. L. Andrew, and N. K. Dulvy. 2009. Vulnerability of national economies to the impacts of climate change on fisheries. Fish and Fisheries 10(2):173-196. https://doi.org/10.1111/j.1467-2979.2008.00310. $\underline{\mathrm{X}}$

Álvarez-Romero, J. G., M. Mills, V. M. Adams, G. G. Gurney, R. L. Pressey, R. Weeks, N. C. Ban, J. Cheok, T. E. Davies, J. C. Day, M. A. Hamel, H. M. Leslie, R. A. Magris, and C. J. Storlie. 2018. Research advances and gaps in marine planning: towards a global database in systematic conservation planning. Biological Conservation 227:369-382. https://doi.org/10.1016/j.biocon.2018.06.027

Anthony, K. R. N., P. A. Marshall, A. Abdulla, R. Beeden, C. Bergh, R. Black, C. M. Eakin, E. T. Game, M. Gooch, N. A. J. Graham, A. Green, S. F. Heron, R. van Hooidonk, C. Knowland, S. Mangubhai, N. Marshall, J. A. Maynard, P. McGinnity, E. McLeod, P. J. Mumby, M. Nyström, D. Obura, J. Oliver, H. P. Possingham, R. L. Pressey, G. P. Rowlands, J. Tamelander, D. Wachenfeld, and S. Wear. 2015. Operationalizing resilience for adaptive coral reef management under global environmental change. Global Change Biology 21(1):48-61. https://doi. org $/ 10.1111 / \mathrm{gcb} .12700$

Aretano, R., T. Semeraro, I. Petrosillo, A. De Marco, M. R. Pasimeni, and G. Zurlini. 2015. Mapping ecological vulnerability to fire for effective conservation management of natural protected areas. Ecological Modelling 295:163-175. https://doi.org/10.1016/ j.ecolmodel.2014.09.017

Armitage, D., F. Berkes, A. Dale, E. Kocho-Schellenberg, and E. Patton. 2011. Co-management and the co-production of knowledge: learning to adapt in Canada's Arctic. Global Environmental Change 21(3):995-1004. https://doi.org/10.1016/j. gloenvcha.2011.04.006

Aselu, B. 2015. A Tuvaluan concept of well-being: reflection on national planning - Te Kakeega II. Thesis. Auckland University of Technology, Auckland, New Zealand.

Aswani, S., X. Basurto, S. Ferse, M. Glaser, L. Campbell, J. E. Cinner, T. Dalton, L. D. Jenkins, M. L. Miller, R. B. Pollnac, I. Vaccaro, and P. Christie. 2018. Marine resource management and conservation in the Anthropocene. Environmental Conservation 45(2):192-202. https://doi.org/10.1017/S0376892917000431

Ayers, J. M., and S. Huq. 2009. Supporting adaptation to climate change: what role for official development assistance? Development Policy Review 27(6):675-692. https://doi.org/10.1111/ j.1467-7679.2009.00465.X

Bacon, C. M., W. A. Sundstrom, I. T. Stewart, and D. Beezer. 2017. Vulnerability to cumulative hazards: coping with the coffee leaf rust outbreak, drought, and food insecurity in Nicaragua. World Development 93:136-152. https://doi.org/10.1016/j. worlddev.2016.12.025

Ban, N. C., M. Mills, J. Tam, C. C. Hicks, S. Klain, N. Stoeck1, M. C. Bottrill, J. Levine, R. L. Pressey, T. Satterfield, and K. M. Chan. 2013. A social-ecological approach to conservation planning: embedding social considerations. Frontiers in Ecology and the Environment 11(4):194-202. https://doi.org/10.1890/110205

Barnett, J., L. S. Evans, C. Gross, A. S. Kiem, R. T. Kingsford, J. P. Palutikof, C. M. Pickering, and S. G. Smithers. 2015. From barriers to limits to climate change adaptation: path dependency and the speed of change. Ecology and Society 20(3):5. https://doi. org/10.5751/ES-07698-200305

Basurto, X., S. Gelcich, and E. Ostrom. 2013. The socialecological system framework as a knowledge classificatory system for benthic small-scale fisheries. Global Environmental Change 23 (6):1366-1380. https://doi.org/10.1016/j.gloenvcha.2013.08.001

Bell, J. D., J. Albert, G. Amos, C. Arthur, M. Blanc, D. Bromhead, S. F. Heron, A. J. Hobday, A. Hunt, D. Itano, P. A. S. James, P. Lehodey, G. Liu, S. Nicol, J. Potemra, G. Reygondeau, J. Rubani, J. Scutt Phillips, I. Senina, and W. Sokimi. 2018. Operationalising access to oceanic fisheries resources by small-scale fishers to improve food security in the Pacific Islands. Marine Policy 88:315-322. https://doi.org/10.1016/j.marpol.2017.11.008

Bell, J., and M. Taylor. 2015. Building climate-resilient food systems for Pacific Islands. WorldFish, Penang, Malaysia.

Belliveau, S., B. Smit, and B. Bradshaw. 2006. Multiple exposures and dynamic vulnerability: evidence from the grape industry in the Okanagan Valley, Canada. Global Environmental Change 16:364-378. https://doi.org/10.1016/j.gloenvcha.2006.03.003

Bennett, N. J., J. Blythe, S. Tyler, and N. C. Ban. 2016. Communities and change in the Anthropocene: understanding social-ecological vulnerability and planning adaptations to multiple interacting exposures. Regional Environmental Change 16(4):907-926. https://doi.org/10.1007/s10113-015-0839-5

Bennett, N. J., P. Dearden, and A. M. Peredo. 2015. Vulnerability to multiple stressors in coastal communities: a study of the 
Andaman coast of Thailand. Climate and Development 7 (2):124-141. https://doi.org/10.1080/17565529.2014.886993

Berkes, F., and N. J. Turner. 2006. Knowledge, learning and the evolution of conservation practice for social-ecological system resilience. Human Ecology 34:479. https://doi.org/10.1007/ s10745-006-9008-2

Beroya-Eitner, M. A. 2016. Ecological vulnerability indicators. Ecological Indicators 60:329-334. https://doi.org/10.1016/j. ecolind.2015.07.001

Berrouet, L. M., J. Machado, and C. Villegas-Palacio. 2018. Vulnerability of socio-ecological systems: a conceptual Framework. Ecological Indicators 84:632-647. https://doi. org/10.1016/j.ecolind.2017.07.051

Binder, C. R., J. Hinkel, P. W. G. Bots, and C. Pahl-Wostl. 2013. Comparison of frameworks for analyzing social-ecological systems. Ecology and Society 18(4):26. https://doi.org/10.5751/ ES-05551-180426

Bird, Z., and L. Yuen. 2020. Climate change and peri-urban household food security - lessons from West Taraka, Morobe Province, Papua New Guinea. Pages 171-195 in W. L. Filho, editor. Managing climate change adaptation in the Pacific region. Springer, Cham, Switzerland. https://doi.org/10.1007/978-3-030-40552-6 9

Blanchard, J. L., R. A. Watson, E. A. Fulton, R. S. Cottrell, K. L. Nash, A. Bryndum-Buchholz, M. Büchner, D. A. Carozza, W. W. L Cheung, J. Elliott, L. N. K Davidson, N. K. Dulvy, J. P. Dunne, T. D. Eddy, E. Galbraith, H. K. Lotze, O. Maury, C. Müller, D. P. Tittensor, and S. Jennings. 2017. Linked sustainability challenges and trade-offs among fisheries, aquaculture and agriculture. Nature Ecology \& Evolution 1:1240-1249. https://doi.org/10.1038/s41559-017-0258-8

Bourgoin, C., J. Oszwald, J. Bourgoin, V. Gond, L. Blanc, H. Dessard, T. Van Phan, P. Sist, P. Läderach, and L. Reymondin. 2020. Assessing the ecological vulnerability of forest landscape to agricultural frontier expansion in the Central Highlands of Vietnam. International Journal of Applied Earth Observation and Geoinformation 84:101958. https://doi.org/10.1016/j.jag.2019.101958

Bousquet, F., M. Anderies, M. Antona, T. Bassett, T. Benjaminsen, O. Bonato, M. Castro, D. Gautier, L. Gunderson, M. Janssen, A. Kinzig, M. Lecoq, T. Lynam, R. Mathevet, C. Perrings, A. Quinlan, and N. Peluso. 2015. Socio-ecological theories and empirical research. Comparing social-ecological schools of thoughts in action. Research Report. CIRAD-GREEN, Montpellier, France.

Brenkert, A. L., and E. L. Malone. 2005. Modeling vulnerability and resilience to climate change: a case study of India and Indian states. Climatic Change 72:57-102. https://doi.org/10.1007/ s10584-005-5930-3

Brugère, C., and C. De Young. 2015. Assessing climate change vulnerability in fisheries and aquaculture: available methodologies and their relevance for the sector. FAO Fisheries and Aquaculture Technical Paper No. 597. Food and Agriculture Organization, Rome, Italy.

Bunce, M., K. Brown, and S. Rosendo. 2010. Policy misfits, climate change and cross-scale vulnerability in coastal Africa: how development projects undermine resilience. Environmental Science \& Policy 13(6):485-497. https://doi.org/10.1016/j. envsci.2010.06.003

Cameron, E. S. 2012. Securing indigenous politics: a critique of the vulnerability and adaptation approach to the human dimensions of climate change in the Canadian Arctic. Global Environmental Change 22(1):103-114. https://doi.org/10.1016/j. gloenvcha.2011.11.004

Chen, C., and D. Lopez-Carr. 2015. The importance of place: unraveling the vulnerability of fisherman livelihoods to the impact of marine protected areas. Applied Geography 59:88-97. https://doi.org/10.1016/j.apgeog.2014.10.015

Chen, C., D. López-Carr, and B. L. E. Walker. 2014. A framework to assess the vulnerability of California commercial sea urchin fishermen to the impact of MPAs under climate change. GeoJournal 79:755-773. https://doi.org/10.1007/s10708-014-9543-0

Christensen, V., C. J. Walters, and D. Pauly. 2004. Ecopath with ecosim: a user's guide. Fisheries Centre, University of British Columbia, Vancouver, Canada.

Cinner, J. E., W. N. Adger, E. H. Allison, M. L. Barnes, K. Brown, P. J. Cohen, S. Gelcich, C. C. Hicks, T. P. Hughes, J. Lau, N. A. Marshall, and T. H. Morrison. 2018. Building adaptive capacity to climate change in tropical coastal communities. Nature Climate Change 8:117-123. https://doi.org/10.1038/s41558-017-0065-X

Cinner, J. E., C. Folke, T. M. Daw, and C. C. Hicks. 2011. Responding to change: using scenarios to understand how socioeconomic factors may influence amplifying or dampening exploitation feedbacks among Tanzanian fishers. Global Environmental Change 21(1):7-12. https://doi.org/10.1016/j. gloenvcha.2010.09.001

Cinner, J. E., C. Huchery, E. S. Darling, A. T. Humphries, N. A. J. Graham, C. C. Hicks, N. Marshall, and T. R. McClanahan. 2013a. Evaluating social and ecological vulnerability of coral reef fisheries to climate change. PLOS ONE 8(9):e74321. https://doi. org/10.1371/journal.pone.0074321

Cinner, J. E., T. R. McClanahan, N. A. J. Graham, T. M. Daw, J. Maina, S. M. Stead, A. Wamukota, K. Brown, and Ö. Bodin. 2012. Vulnerability of coastal communities to key impacts of climate change on coral reef fisheries. Global Environmental Change 22(1):12-20. https://doi.org/10.1016/j.gloenvcha.2011.09.018

Cinner, J. E., T. R. McClanahan, A. Wamukota, E. S. Darling, A. T. Humphries, C. C. Hicks, C. Huchery, N. A. Marshall, T. Hempson, N. A. J. Graham, Ö. Bodin, T. M. Daw, E. H. Allison, and FAO. 2013b. Social-ecological vulnerability of coral reef fisheries to climatic shocks. Food and Agriculture Organization, Rome, Italy.

Clark, W. C., and N. M. Dickson. 2003. Sustainability science: the emerging research program. Proceedings of the National Academy of Sciences of the United States of America 100 (14):8086-8091. https://doi.org/10.1073/pnas.1231333100

Claudet, J., L. Bopp, W. W. L. Cheung, R. Devillers, E. EscobarBriones, P. Haugan, J. J. Heymans, V. Masson-Delmotte, N. MatzLück, P. Miloslavich, L. Mullineaux, M. Visbeck, R. Watson, A. M. Zivian, I. Ansorge, M. Araujo, S. Aricò, D. Bailly, J. Barbière, 
C. Barnerias, C. Bowler, V. Brun, A. Cazenave, C. Diver, A. Euzen, A. T. Gaye, N. Hilmi, F. Ménard, C. Moulin, N. P. Muñoz, R. Parmentier, A. Pebayle, H.-O. Pörtner, S. Osvaldina, P. Ricard, R. S. Santos, M.-A. Sicre, S. Thiébault, T. Thiele, R. Troublé, A. Turra, J. Uku, and F. Gaill. 2020. A roadmap for using the UN Decade of Ocean Science for Sustainable Development in support of science, policy, and action. One Earth 2(1):34-42. https://doi. org/10.1016/j.oneear.2019.10.012

Cochran, P. A. L., C. A. Marshall, C. Garcia-Downing, E. Kendall, D. Cook, L. McCubbin, and R. M. S. Gover. 2008. Indigenous ways of knowing: implications for participatory research and community. American Journal of Public Health 98 (1):22-27. https://doi.org/10.2105/AJPH.2006.093641

Cochrane, K. L., H. Rakotondrazafy, S. Aswani, T. Chaigneau, N. Downey-Breedt, A. Lemahieu, A. Paytan, G. Pecl, E. Plagányi, E. Popova, E. I. van Putten, W. H. H. Sauer, V. Byfield, M. A. Gasalla, S. J. van Gennip, W. Malherbe, A. Rabary, A. Rabearisoa, N. Ramaroson, V. Randrianarimanana, L. Scott, and P. M. Tsimanaoraty. 2019. Tools to enrich vulnerability assessment and adaptation planning for coastal communities in data-poor regions: application to a case study in Madagascar. Frontiers in Marine Science 5:505. https://doi.org/10.3389/fmars.2018.00505

Comte, A., L. H. Pendleton, D. Bailly, and E. Quillérou. 2019. Conceptual advances on global scale assessments of vulnerability: informing investments for coastal populations at risk of climate change. Marine Policy 99:391-399. https://doi.org/10.1016/j. marpol.2018.10.038

Dacks, R., T. Ticktin, A. Mawyer, S. Caillon, J. Claudet, P. Fabre, S. D. Jupiter, J. McCarter, M. Mejia, P. Pascua, E. Sterling, and S. Wongbusarakum. 2019. Developing biocultural indicators for resource management. Conservation Science and Practice 1(6): e38. https://doi.org/10.1111/csp2.38

Day, J. C., S. F. Heron, A. Markham, J. Downes, J. Gibson, E. Hyslop, R. H. Jones, and A. Lyall. 2019. Climate risk assessment for the heart of Neolithic Orkney World Heritage Site: an application of the climate vulnerability index. Historic Environment Scotland, Edinburgh, UK.

de Sherbinin, A., A. Bukvic, G. Rohat, M. Gall, B. McCusker, B. Preston, A. Apotsos, C. Fish, S. Kienberger, P. Muhonda, O. Wilhelmi, D. Macharia, W. Shubert, R. Sliuzas, B. Tomaszewski, and S. Zhang. 2019. Climate vulnerability mapping: a systematic review and future prospects. Wiley Interdisciplinary Reviews: Climate Change 10(5):e600. https://doi.org/10.1002/wcc.600

Debortoli, N. S., J. S. Sayles, D. G. Clark, and J. D. Ford. 2018. A systems network approach for climate change vulnerability assessment. Environmental Research Letters 13:104019. https:// doi.org/10.1088/1748-9326/aae24a

Depietri, Y. 2020. The social-ecological dimension of vulnerability and risk to natural hazards. Sustainability Science 15:587-604. https://doi.org/10.1007/s11625-019-00710-y

Dubois, N., A. Caldas, J. Boshoven, and A. Delach. 2011. Integrating climate change vulnerability assessments into adaptation planning: a case study using the NatureServe Climate Change Vulnerability Index to inform conservation planning for species in Florida. Defenders of Wildlife, Washington, D.C., USA.
Eakin, H., and L. A. Bojórquez-Tapia. 2008. Insights into the composition of household vulnerability from multicriteria decision analysis. Global Environmental Change 18(1):112-127. https://doi.org/10.1016/j.gloenvcha.2007.09.001

Eakin, H., and A. L. Luers. 2006. Assessing the vulnerability of social-environmental systems. Annual Review of Environment and Resources 31(1):365-394. https://doi.org/10.1146/annurev. energy.30.050504.144352

Eierdanz, F., J. Alcamo, L. Acosta-Michlik, D. Krömker, and D. Tänzler. 2008. Using fuzzy set theory to address the uncertainty of susceptibility to drought. Regional Environmental Change 8:197-205. https://doi.org/10.1007/s10113-008-0069-1

Ekstrom, J. A., L. Suatoni, S. R. Cooley, L. H. Pendleton, G. G. Waldbusser, J. E. Cinner, J. Ritter, C. Langdon, R. van Hooidonk, D. Gledhill, K. Wellman, M. W. Beck, L. M. Brander, D. Rittschof, C. Doherty, P. E. T. Edwards, and R. Portela. 2015. Vulnerability and adaptation of US shellfisheries to ocean acidification. Nature Climate Change 5:207-214. https://doi. org/10.1038/nclimate2508

Fawcett, D., T. Pearce, J. D. Ford, and L. Archer. 2017. Operationalizing longitudinal approaches to climate change vulnerability assessment. Global Environmental Change 45:79-88. https://doi.org/10.1016/j.gloenvcha.2017.05.002

Finkbeiner, E. M., F. Micheli, N. J. Bennett, A. L. Ayers, E. Le Cornu, and A. N. Doerr. 2018. Exploring trade-offs in climate change response in the context of Pacific Island fisheries. Marine Policy 88:359-364. https://doi.org/10.1016/j.marpol.2017.09.032

Fischer, J., T. A. Gardner, E. M. Bennett, P. Balvanera, R. Biggs, S. Carpenter, T. M. Daw, C. Folke, R. Hill, T. P. Hughes, T. Luthe, M. Maass, M. Meacham, A. V. Norström, G. Peterson, C. Queiroz, R. Seppelt, M. Spierenburg, and J. Tenhunen. 2015. Advancing sustainability through mainstreaming a socialecological systems perspective. Current Opinion in Environmental Sustainability 14:144-149. https://doi.org/10.1016/i.cosust.2015.06.002

Fischer, J., and M. Riechers. 2019. A leverage points perspective on sustainability. People and Nature 1(1):115-120. https://doi. org/10.1002/pan3.13

Fischhoff, B. 2013. The sciences of science communication. Proceedings of the National Academy of Sciences of the United States of America 110(SUPPL3):14033-14039. https://doi. org/10.1073/pnas.1213273110

Foden, W. B., S. H. M. Butchart, S. N. Stuart, J.-C. Vié, H. R. Akçakaya, A. Angulo, L. M. DeVantier, A. Gutsche, E. Turak, L. Cao, S. D. Donner, V. Katariya, R. Bernard, R. A. Holland, A. F. Hughes, S. E. O'Hanlon, S. T. Garnett, Ç. H. Şekercioğlu, and G. M. Mace. 2013. Identifying the world's most climate change vulnerable species: a systematic trait-based assessment of all birds, amphibians and corals. PLoS ONE 8(6):e65427. https:// doi.org/10.1371/journal.pone.0065427

Foden, W. B., B. E. Young, H. R. Akçakaya, R. A. Garcia, A. A. Hoffmann, B. A. Stein, C. D. Thomas, C. J. Wheatley, D. Bickford, J. A. Carr, D. G. Hole, T. G. Martin, M. Pacifici, J. W. PearceHiggins, P. J. Platts, P. Visconti, J. E. M. Watson, and B. Huntley. 2019. Climate change vulnerability assessment of species. Wiley 
Interdisciplinary Reviews: Climate Change 10(1):e551. https://doi. org/10.1002/wcc.551

Folke, C., R. Biggs, A. V. Norström, B. Reyers, and J. Rockström. 2016. Social-ecological resilience and biosphere-based sustainability science. Ecology and Society 21(3):41. https://doi.org/10.5751/ ES-08748-210341

Ford, J. D., G. McDowell, J. Shirley, M. Pitre, R. Siewierski, W. Gough, F. Duerden, T. Pearce, P. Adams, and S. Statham. 2013. The dynamic multiscale nature of climate change vulnerability: an Inuit harvesting example. Annals of the Association of American Geographers 103(5):1193-1211. https://doi. org/10.1080/00045608.2013.776880

Füssel, H.-M. 2007. Vulnerability: a generally applicable conceptual framework for climate change research. Global Environmental Change 17(2):155-167. https://doi.org/10.1016/j. gloenvcha.2006.05.002

Gallopín, G. C. 2006. Linkages between vulnerability, resilience, and adaptive capacity. Global Environmental Change 16(3):293303. https://doi.org/10.1016/j.gloenvcha.2006.02.004

Gavin, M. C., J. McCarter, A. Mead, F. Berkes, J. R. Stepp, D. Peterson, and R. Tang. 2015. Defining biocultural approaches to conservation. Trends in Ecology and Evolution 30(3):140-145. https://doi.org/10.1016/j.tree.2014.12.005

Guerrero, A. M., N. J. Bennett, K. A. Wilson, N. Carter, D. Gill, M. Mills, C. D. Ives, M. J. Selinske, C. Larrosa, S. Bekessy, F. A. Januchowski-Hartley, H. Travers, C. A. Wyborn, and A. Nuno. 2018. Achieving the promise of integration in social-ecological research: a review and prospectus. Ecology and Society 23(3):38. https://doi.org/10.5751/ES-10232-230338

Gurney, G. G., E. S. Darling, S. D. Jupiter, S. Mangubhai, T. R. McClanahan, P. Lestari, S. Pardede, S. J. Campbell, M. Fox, W. Naisilisili, N. A. Muthiga, S. D'agata, K. E. Holmes, and N. A. Rossi. 2019. Implementing a social-ecological systems framework for conservation monitoring: lessons from a multi-country coral reef program. Biological Conservation 240:108298. https://doi. org/10.1016/j.biocon.2019.108298

Haalboom, B., and D. C. Natcher. 2012. The power and peril of "vulnerability": approaching community labels with caution in climate change research. Arctic 65(3):319-327. https://doi. org/10.14430/arctic4219

Hallegatte, S., V. Przyluski, and A. Vogt-Schilb. 2011. Building world narratives for climate change impact, adaptation and vulnerability analyses. Nature Climate Change 1:151-155. https:// doi.org/10.1038/nclimate1135

Halpern, B. S., and R. Fujita. 2013. Assumptions, challenges, and future directions in cumulative impact analysis. Ecosphere 4 (10):1-11. https://doi.org/10.1890/ES13-00181.1

Heltberg, R., P. B. Siegel, and S. L. Jorgensen. 2009. Addressing human vulnerability to climate change: toward a 'no-regrets' approach. Global Environmental Change 19(1):89-99. https://doi. org/10.1016/j.gloenvcha.2008.11.003

Hinkel, J. 2011. "Indicators of vulnerability and adaptive capacity": towards a clarification of the science-policy interface. Global Environmental Change 21(1):198-208. https://doi. org/10.1016/j.gloenvcha.2010.08.002
Humphries, A. T., L. I. Josephs, M. K. La Peyre, S. Hall, and R. Dowty Beech. 2019. Vulnerability of resource users in Louisiana's oyster fishery to environmental hazards. Ecology and Society 24 (3):37. https://doi.org/10.5751/es-11101-240337

Huynh, L. T. M., and L. C. Stringer. 2018. Multi-scale assessment of social vulnerability to climate change: an empirical study in coastal Vietnam. Climate Risk Management 20:165-180. https:// doi.org/10.1016/j.crm.2018.02.003

Ibbett, H., and S. Brittain. 2020. Conservation publications and their provisions to protect research participants. Conservation Biology 34(1):80-92. https://doi.org/10.1111/cobi.13337

Intergovernmental Panel on Climate Change (IPCC). 2001. Climate change 2001: impacts, adaptation, and vulnerability. Contribution of Working Group II to the Third Assessment Report of the Intergovernmental Panel on Climate Change J. J. McCarthy, O. F. Canziani, N. A. Leary, D. J. Dokken, and K. S. White, editors. Cambridge University press, Cambridge, UK.

Intergovernmental Panel on Climate Change (IPCC). 2007. Climate change 2007 synthesis report. Contribution of Working Groups I, II and III to the Fourth Assessment Report of the Intergovernmental Panel on Climate Change. Core Writing Team, R. K. Pachauri, and A. Reisinger, editors. IPCC, Geneva, Switzerland.

Intergovernmental Panel on Climate Change (IPCC). 2014. Climate Change 2014: Synthesis Report. Contribution of Working Groups I, II and III to the Fifth Assessment Report of the Intergovernmental Panel on Climate Change. Core Writing Team, R. K. Pachauri, and L. A. Meyer, editors. IPCC, Geneva, Switzerland.

Intergovernmental Science-Policy Platform on Biodiversity and Ecosystem Services (IPBES). 2019. Summary for policymakers of the global assessment report on biodiversity and ecosystem services of the Intergovernmental Science-Policy Platform on Biodiversity and Ecosystem Services. S. Díaz, J. Settele, E. S. Brondízio E.S., H. T. Ngo, M. Guèze, J. Agard, A. Arneth, P. Balvanera, K. A. Brauman, S. H. M. Butchart, K. M. A. Chan, L. A. Garibaldi, K. Ichii, J. Liu, S. M. Subramanian, G. F. Midgley, P. Miloslavich, Z. Molnár, D. Obura, A. Pfaff, S. Polasky, A. Purvis, J. Razzaque, B. Reyers, R. Roy Chowdhury, Y. J. Shin, I. J. Visseren-Hamakers, K. J. Willis, and C. N. Zayas, editors. IPBES Secretariat, Bonn, Germany.

Ippolito, A., S. Sala, J. H. Faber, and M. Vighi. 2010. Ecological vulnerability analysis: a river basin case study. Science of the Total Environment 408(18):3880-3890. https://doi.org/10.1016/j. scitotenv.2009.10.002

Johnson, J. E. and P. A. Marshall, editors. 2007. Climate change and the Great Barrier Reef. Great Barrier Reef Marine Park Authority and Australian Greenhouse Office, Canberra, Australia

Johnson, J. E., and D. J. Welch. 2016. Climate change implications for Torres Strait fisheries: assessing vulnerability to inform adaptation. Climatic Change 135:611-624. https://doi.org/10.1007/ s10584-015-1583-Z

Johnson, J. E., D. J. Welch, J. A. Maynard, J. D. Bell, G. Pecl, J. Robins, and T. Saunders. 2016. Assessing and reducing vulnerability to climate change: moving from theory to practical 
decision-support. Marine Policy 74:220-229. https://doi. org/10.1016/j.marpol.2016.09.024

Jones, L. 2019. Resilience isn't the same for all: comparing subjective and objective approaches to resilience measurement. Wiley Interdisciplinary Reviews: Climate Change 10(1):e552. https://doi.org/10.1002/wcc.552

Jones, M. C., and W. W. L. Cheung. 2018. Using fuzzy logic to determine the vulnerability of marine species to climate change. Global Change Biology 24(2):e719-e731. https://doi.org/10.1111/ gcb. 13869

Kasperson, J. X., R. E. Kasperson, B. L. Turner, W. Hseih, and A. Schiller. 2005. Vulnerability to global environmental change. Pages 245-285 in R. E. Kasperson and J. Kasperson, editors. Social contours of risk: Volume II: risk analysis, corporations and the globalization of risk. Routledge, London, UK.

Kittinger, J. N., J. Z. Koehn, E. Le Cornu, N. C. Ban, M. Gopnik, M. Armsby, C. Brooks, M. H. Carr, J. E. Cinner, A. Cravens, M. D’Iorio, A. Erickson, E. M. Finkbeiner, M. M. Foley, R. Fujita, S. Gelcich, K. S. Martin, E. Prahler, D. R. Reineman, J. Shackeroff, C. White, M. R. Caldwell, and L. B. Crowder. 2014. A practical approach for putting people in ecosystem-based ocean planning. Frontiers in Ecology and the Environment 12(8):448-456. https://doi.org/10.1890/130267

Kok, M., M. Lüdeke, P. Lucas, T. Sterzel, C. Walther, P. Janssen, D. Sietz, and I. de Soysa. 2016. A new method for analysing socioecological patterns of vulnerability. Regional Environmental Change 16:229-243. https://doi.org/10.1007/s10113-014-0746-1

Kutz, S., and M. Tomaselli. 2019. "Two-eyed seeing” supports wildlife health. Science 364(6446):1135-1137. https://doi. org/10.1126/science.aau6170

Lapola, D. M., J. M. C. da Silva, D. R. Braga, L. Carpigiani, F. Ogawa, R. R. Torres, L. C. F. Barbosa, J. P. H. B. Ometto, and C. A. Joly. 2019. A climate-change vulnerability and adaptation assessment for Brazil's protected areas. Conservation Biology 34 (2):427-437. https://doi.org/10.1111/cobi.13405

Lebot, V., and P. Siméoni. 2015. Community food security: resilience and vulnerability in Vanuatu. Human Ecology 43:827-842. https://doi.org/10.1007/s10745-015-9796-3

Leichenko, R. M., and K. L. O'Brien. 2002. The dynamics of rural vulnerability to global change: the case of Southern Africa. Mitigation and Adaptation Strategies for Global Change 7:1-18. https://doi.org/10.1023/A:1015860421954

Lemos, M. C., A. Agrawal, H. Eakin, D. R. Nelson, N. L. Engle, and O. Johns. 2013. Building adaptive capacity to climate change in less developed countries. Pages 437-457 in G. R. Asrar and J. W. Hurrell, editors. Climate science for serving society: research, modeling and prediction priorities. Springer, Netherlands, Dordrecht. https://doi.org/10.1007/978-94-007-6692-1 16

Lemos, M. C., J. C. Arnott, N. M. Ardoin, K. Baja, A. T. Bednarek, A. Dewulf, C. Fieseler, K. A. Goodrich, K. Jagannathan, N. Klenk, K. J. Mach, A. M. Meadow, R. Meyer, R. Moss, L. Nichols, K. D. Sjostrom, M. Stults, E. Turnhout, C. Vaughan, G. Wong-Parodi, and C. Wyborn. 2018. To co-produce or not to co-produce. Nature Sustainability 1:722-724. https://doi. org/10.1038/s41893-018-0191-0
Lemos, M. C., Y. J. Lo, D. R. Nelson, H. Eakin, and A. M. BedranMartins. 2016. Linking development to climate adaptation: leveraging generic and specific capacities to reduce vulnerability to drought in NE Brazil. Global Environmental Change 39:170179. https://doi.org/10.1016/j.gloenvcha.2016.05.001

Lowndes, J. S. S., B. D. Best, C. Scarborough, J. C. Afflerbach, M. R. Frazier, C. C. O’Hara, N. Jiang, and B. S. Halpern. 2017. Our path to better science in less time using open data science tools. Nature Ecology \& Evolution 1:0160. https://doi.org/10.1038/ s41559-017-0160

Luers, A. L. 2005. The surface of vulnerability: an analytical framework for examining environmental change. Global Environmental Change 15(3):214-223. https://doi.org/10.1016/j. gloenvcha.2005.04.003

Maina, J., J. Kithiia, J. Cinner, E. Neale, S. Noble, D. Charles, and J. E. M. Watson. 2016. Integrating social-ecological vulnerability assessments with climate forecasts to improve local climate adaptation planning for coral reef fisheries in Papua New Guinea. Regional Environmental Change 16:881-891. https://doi. org/10.1007/s10113-015-0807-0

Marshall, N. A., M. I. Curnock, J. Goldberg, M. Gooch, P. A. Marshall, P. L. Pert, and R. C. Tobin. 2017. The dependency of people on the Great Barrier Reef, Australia. Coastal Management 45(6):505-518. https://doi.org/10.1080/08920753.2017.1373454

Marshall, N. A., P. A. Marshall, J. Tamelander, D. Obura, D. Malleret-King, and J. E. Cinner. 2009. A framework for social adaptation to climate change sustaining tropical coastal communitites and industries. International Union for Conservation of Nature, Gland, Switzerland.

McClanahan, T. R., J. E. Cinner, J. Maina, N. A. J. Graham, T. M. Daw, S. M. Stead, A. Wamukota, K. Brown, M. Ateweberhan, V. Venus, and N. V. C. Polunin. 2008. Conservation action in a changing climate. Conservation Letters 1:53-59. https://doi. org/10.1111/j.1755-263X.2008.00008 1.X

McDowell, J. Z., and J. J. Hess. 2012. Accessing adaptation: multiple stressors on livelihoods in the Bolivian highlands under a changing climate. Global Environmental Change 22(2):342-352. https://doi.org/10.1016/j.gloenvcha.2011.11.002

Mcleod, E., K. R. N. Anthony, P. J. Mumby, J. Maynard, R. Beeden, N. A. J. Graham, S. F. Heron, O. Hoegh-Guldberg, S. Jupiter, P. MacGowan, S. Mangubhai, N. Marshall, P. A. Marshall, T. R. McClanahan, K. Mcleod, M. Nyström, D. Obura, B. Parker, H. P. Possingham, R. V. Salm, and J. Tamelander. 2019. The future of resilience-based management in coral reef ecosystems. Journal of Environmental Management 233:291-301. https://doi.org/10.1016/j.jenvman.2018.11.034

McMillen, H. L., T. Ticktin, A. Friedlander, S. D. Jupiter, R. Thaman, J. Campbell, J. Veitayaki, T. Giambelluca, S. Nihmei, E. Rupeni, L. Apis-Overhoff, W. Aalbersberg, and D. F. Orcherton. 2014. Small islands, valuable insights: systems of customary resource use and resilience to climate change in the Pacific. Ecology and Society 19(4):44. https://doi.org/10.5751/ ES-06937-190444

Metcalf, S. J., E. I. van Putten, S. Frusher, N. A. Marshall, M. Tull, N. Caputi, M. Haward, A. J. Hobday, N. J. Holbrook, S. M. Jennings, G. T. Pecl, and J. L. Shaw. 2015. Measuring the 
vulnerability of marine social-ecological systems: a prerequisite for the identification of climate change adaptations. Ecology and Society 20(2):35. https://doi.org/10.5751/ES-07509-200235

Midgley, G. 2000. Boundary critique. Pages 135-158 in Systemic intervention: philosophy, methodology, and practice. Contemporary systems thinking. Springer, New York, New York, USA. https:// doi.org/10.1007/978-1-4615-4201-8 7

Monnereau, I., R. Mahon, P. McConney, L. Nurse, R. Turner, and H. Vallès. 2017. The impact of methodological choices on the outcome of national-level climate change vulnerability assessments: an example from the global fisheries sector. Fish and Fisheries 18(4):717-731. https://doi.org/10.1111/faf.12199

Mora, C., I. R. Caldwell, J. M. Caldwell, M. R. Fisher, B. M. Genco, and S. W. Running. 2015. Suitable days for plant growth disappear under projected climate change: potential human and biotic vulnerability. PLoS Biology 13(6):e1002167. https://doi. org/10.1371/journal.pbio.1002167

Mora, C., D. Spirandelli, E. C. Franklin, J. Lynham, M. B. Kantar, W. Miles, C. Z. Smith, K. Freel, J. Moy, L. V. Louis, E. W. Barba, K. Bettinger, A. G. Frazier, J. F. Colburn IX, N. Hanasaki, E. Hawkins, Y. Hirabayashi, W. Knorr, C. M. Little, K. Emanuel, J. Sheffield, J. A. Patz, and C. L. Hunter. 2018. Broad threat to humanity from cumulative climate hazards intensified by greenhouse gas emissions. Nature Climate Change 8:1062-1071. https://doi.org/10.1038/s41558-018-0315-6

Morel, A. C., M. Hirons, S. Demissie, T. Gonfa, Z. Mehrabi, P. R. Long, S. Rifai, T. Woldemariam Gole, J. Mason, C. L. McDermott, E. Boyd, E. J. Z. Robinson, Y. Malhi, and K. Norris. 2019. The structures underpinning vulnerability: examining landscape-society interactions in a smallholder coffee agroforestry system. Environmental Research Letters 14 (7):075006. https://doi.org/10.1088/1748-9326/ab2280

Müller, B., L. Johnson, and D. Kreuer. 2017. Maladaptive outcomes of climate insurance in agriculture. Global Environmental Change 46:23-33. https://doi.org/10.1016/j. gloenvcha.2017.06.010

Mumby, P. J., I. Chollett, Y.-M. Bozec, and N. H. Wolff. 2014. Ecological resilience, robustness and vulnerability: how do these concepts benefit ecosystem management? Current Opinion in Environmental Sustainability 7:22-27. https://doi.org/10.1016/j. cosust.2013.11.021

Næss, L. O., G. Bang, S. Eriksen, and J. Vevatne. 2005. Institutional adaptation to climate change: flood responses at the municipal level in Norway. Global Environmental Change 15 (2):125-138. https://doi.org/10.1016/j.gloenvcha.2004.10.003

National Academies of Sciences, Engineering, and Medicine. 2017. Communicating science effectively: a research agenda. National Academies Press, Washington, D.C., USA. https://doi. org/10.17226/23674

Naylor, A., J. Ford, T. Pearce, and J. Van Alstine. 2020. Conceptualizing climate vulnerability in complex adaptive systems. One Earth 2(5):444-454. https://doi.org/10.1016/j. oneear.2020.04.011

Nicotra, A. B., E. A. Beever, A. L. Robertson, G. E. Hofmann, and J. O'Leary. 2015. Assessing the components of adaptive capacity to improve conservation and management efforts under global change. Conservation Biology 29(5):1268-1278. https://doi. org/10.1111/cobi.12522

Norström, A. V., C. Cvitanovic, M. F. Löf, S. West, C. Wyborn, P. Balvanera, A. T. Bednarek, E. M. Bennett, R. Biggs, A. de Bremond, B. M. Campbell, J. G. Canadell, S. R. Carpenter, C. Folke, E. A. Fulton, O. Gaffney, S. Gelcich, J. Jouffray, M. Leach, M. Le Tissier, B. Martín-López, E. Louder, M. Loutre, A. M. Meadow, H. Nagendra, D. Payne, G. D. Peterson, B. Reyers, R. Scholes, C. I. Speranza, M. Spierenburg, M. Stafford-Smith, M. Tengö, S. van der Hel, I. van Putten, and H. Österblom. 2020. Principles for knowledge co-production in sustainability research. Nature Sustainability 3:182-190. https://doi.org/10.1038/s41893-019-0448-2

O'Brien, K. L., and R. M. Leichenko. 2000. Double exposure: assessing the impacts of climate change within the context of economic globalization. Global Environmental Change 10:221-232. https://doi.org/10.1016/S0959-3780(00)00021-2

O’Brien, K., R. Leichenko, U. Kelkar, H. Venema, G. Aandahl, H. Tompkins, A. Javed, S. Bhadwal, S. Barg, L. Nygaard, and J. West. 2004. Mapping vulnerability to multiple stressors: climate change and globalization in India. Global Environmental Change 14:303-313. https://doi.org/10.1016/j.gloenvcha.2004.01.001

Oberlack, C., L. Tejada, P. Messerli, S. Rist, and M. Giger. 2016. Sustainable livelihoods in the global land rush? Archetypes of livelihood vulnerability and sustainability potentials. Global Environmental Change 41:153-171. https://doi.org/10.1016/j. gloenvcha.2016.10.001

Okey, T. A., S. Agbayani, and H. M. Alidina. 2015. Mapping ecological vulnerability to recent climate change in Canada's Pacific marine ecosystems. Ocean and Coastal Management 106:35-48. https://doi.org/10.1016/j.ocecoaman.2015.01.009

Ostrom, E. 2009. A general framework for analyzing sustainability of social-ecological systems. Science 325 (5939):419-422. https://doi.org/10.1126/science.1172133

Pacifici, M., W. B. Foden, P. Visconti, J. E. M. Watson, S. H. M. Butchart, K. M. Kovacs, B. R. Scheffers, D. G. Hole, T. G. Martin, H. R. Akçakaya, et al. 2015. Assessing species vulnerability to climate change. Nature Climate Change 5:215-224. https://doi. org/10.1038/nclimate2448

Parravicini, V., S. Villéger, T. R. McClanahan, J. E. AriasGonzález, D. R. Bellwood, J. Belmaker, P. Chabanet, S. R. Floeter, A. M. Friedlander, F. Guilhaumon, L. Vigliola, M. Kulbicki, and D. Mouillot. 2014. Global mismatch between species richness and vulnerability of reef fish assemblages. Ecology Letters 17 (9):1101-1110. https://doi.org/10.1111/ele.12316

Parrott, L., and W. S. Meyer. 2012. Future landscapes: managing within complexity. Frontiers in Ecology and the Environment 10 (7):382-389. https://doi.org/10.1890/110082

Pomeroy, R., A. J. Ferrer, and J. Pedrajas. 2017. An analysis of livelihood projects and programs for fishing communities in the Philippines. Marine Policy 81:250-255. https://doi.org/10.1016/j. marpol.2017.04.008

Reed, M. S. 2008. Stakeholder participation for environmental management: a literature review. Biological Conservation 141 (10):2417-2431. https://doi.org/10.1016/j.biocon.2008.07.014 
Reed, M. S., A. Graves, N. Dandy, H. Posthumus, K. Hubacek, J. Morris, C. Prell, C. H. Quinn, and L. C. Stringer. 2009. Who's in and why? A typology of stakeholder analysis methods for natural resource management. Journal of Environmental Management 90(5):1933-1949. https://doi.org/10.1016/j. jenvman.2009.01.001

Saldaña-Zorrilla, S. O. 2008. Stakeholders' views in reducing rural vulnerability to natural disasters in Southern Mexico: hazard exposure and coping and adaptive capacity. Global Environmental Change 18:583-597. https://doi.org/10.1016/j.gloenvcha.2008.09.004

Schipper, E. L. F. 2020. Maladaptation: when adaptation to climate change goes very wrong. One Earth 3(4):409-414. https:// doi.org/10.1016/j.oneear.2020.09.014

Sietz, D., M. K. B. Lüdeke, and C. Walther. 2011. Categorisation of typical vulnerability patterns in global drylands. Global Environmental Change 21:431-440. https://doi.org/10.1016/j. gloenvcha.2010.11.005

Sietz, D., J. C. Ordoñez, M. T. J. Kok, P. Janssen, H. B. M. Hilderink, P. Tittonell, and H. Van Dijk. 2017. Nested archetypes of vulnerability in African drylands: where lies potential for sustainable agricultural intensification. Environmental Research Letters 12(9):095006. https://doi.org/10.1088/1748-9326/aa768b

Singh, P. K., and A. Nair. 2014. Livelihood vulnerability assessment to climate variability and change using fuzzy cognitive mapping approach. Climatic Change 127:475-491. https://doi. org/10.1007/s10584-014-1275-0

Skroblin, A., T. Carboon, G. Bidu, N. Chapman, M. Miller, K. Taylor, W. Taylor, E. T. Game, and B. A. Wintle. 2019. Including Indigenous knowledge in species distribution modeling for increased ecological insights. Conservation Biology. https://doi. org/10.1111/cobi.13373

Smith, E. F., S. N. Lieske, N. Keys, and T. F. Smith. 2016. Rapid regional-scale assessments of socio-economic vulnerability to climate change. Environmental Research Letters 11(3):034016. https://doi.org/10.1088/1748-9326/11/3/034016

SPC-SPREP-GIZ (Pacific Community-Secretariat of the Pacific Regional Environment Programme-Deutsche Gesellschaft für Internationale Zusammenarbeit). 2016. Integrated vulnerability assessment framework for Atoll Islands: a collaborative approach. SPC, Noumea, New Caledonia, SPREP, Apia, Samoa, and GIZ, Bonn, Germany.

Stelzenmüller, V., M. Coll, A. D. Mazaris, S. Giakoumi, S. Katsanevakis, M. E. Portman, R. Degen, P. Mackelworth, A. Gimpel, P. G. Albano, V. Almpanidou, J. Claudet, F. Essl, T. Evagelopoulos, J. J. Heymans, T. Genov, S. Kark, F. Micheli, M. G. Pennino, G. Rilov, B. Rumes, J. Steenbeek, and H. Ojaveer. 2018. A risk-based approach to cumulative effect assessments for marine management. Science of the Total Environment 612:1132-1140. https://doi.org/10.1016/j.scitotenv.2017.08.289

Sterling, E. J., C. Filardi, A. Toomey, A. Sigouin, E. Betley, N. Gazit, J. Newell, S. Albert, D. Alvira, N. Bergamini, M. Blair, D. Boseto, K. Burrows, N. Bynum, S. Caillon, J. E. Caselle, J. Claudet, G. Cullman, R. Dacks, P. B. Eyzaguirre, S. Gray, J. Herrera, P. Kenilorea, K. Kinney, N. Kurashima, S. Macey, C. Malone, S.
Mauli, J. McCarter, H. McMillen, P. Pascua, P. Pikacha, A. L. Porzecanski, P. de Robert, M. Salpeteur, M. Sirikolo, M. H. Stege, K. Stege, T. Ticktin, R. Vave, A. Wali, P. West, K. B. Winter, and S. D. Jupiter. 2017. Biocultural approaches to well-being and sustainability indicators across scales. Nature Ecology \& Evolution 1(12):1798-1806. https://doi.org/10.1038/s41559-017-0349-6

Stock, A., and F. Micheli. 2016. Effects of model assumptions and data quality on spatial cumulative human impact assessments. Global Ecology and Biogeography 25(11):1321-1332. https://doi.org/10.1111/geb.12493

Talley, J. L., J. Schneider, and E. Lindquist. 2016. A simplified approach to stakeholder engagement in natural resource management: The Five-Feature Framework. Ecology and Society 21(4):38. https://doi.org/10.5751/ES-08830-210438

Tengö, M., E. S. Brondizio, T. Elmqvist, P. Malmer, and M. Spierenburg. 2014. Connecting diverse knowledge systems for enhanced ecosystem governance: the multiple evidence base approach. Ambio 43(5):579-591. https://doi.org/10.1007/s13280-014-0501-3

Thiault, L., S. Gelcich, J. E. Cinner, S. Tapia-Lewin, F. Chlous, and J. Claudet. 2019b. Generic and specific facets of vulnerability for analysing trade-offs and synergies in natural resource management. People and Nature 1(4):573-589. https://doi. org/10.1002/pan3.10056

Thiault, L., S. Gelcich, N. Marshall, P. Marshall, F. Chlous, and J. Claudet. 2020. Operationalizing vulnerability for socialecological integration in conservation and natural resource management. Conservation Letters 13(1):e12677. https://doi. org/10.1111/conl.12677

Thiault, L., P. Marshall, S. Gelcich, A. Collin, F. Chlous, and J. Claudet. 2018a. Mapping social-ecological vulnerability to inform local decision making. Conservation Biology 32 (2):447-456. https://doi.org/10.1111/cobi.12989

Thiault, L., P. Marshall, S. Gelcich, A. Collin, F. Chlous, and J. Claudet. 2018b. Space and time matter in social-ecological vulnerability assessments. Marine Policy 88:213-221. https://doi. org/10.1016/j.marpol.2017.11.027

Thiault, L., C. Mora, J. E. Cinner, W. W. L. Cheung, N. A. J. Graham, F. A. Januchowski-Hartley, D. Mouillot, U. R. Sumaila, and J. Claudet. 2019a. Escaping the perfect storm of simultaneous climate change impacts on agriculture and marine fisheries. Science Advances 5(11):eaaw9976. https://doi.org/10.1126/sciadv. aaw9976

Thomas, K. A., and B. P. Warner. 2019. Weaponizing vulnerability to climate change. Global Environmental Change 57:101928. https://doi.org/10.1016/j.gloenvcha.2019.101928

Thompson, C., T. Johnson, and S. Hanes. 2016. Vulnerability of fishing communities undergoing gentrification. Journal of Rural Studies 45:165-174. https://doi.org/10.1016/j.jrurstud.2016.03.008

Ticktin, T., S. Quazi, R. Dacks, M. Tora, A. McGuigan, Z. Hastings, and A. Naikatini. 2018. Linkages between measures of biodiversity and community resilience in Pacific Island agroforests. Conservation Biology 32(5):1085-1095. https://doi. org/10.1111/cobi.13152 
Tilley, A., P. Herrón, S. Espinosa, J. López-Angarita, and S. Box. 2018. Predicting vulnerability to management changes in datalimited, small-scale fisheries. Marine Policy 94:39-45. https://doi. org/10.1016/j.marpol.2018.04.013

Tol, R. S. J., and G. W. Yohe. 2007. The weakest link hypothesis for adaptive capacity: an empirical test. Global Environmental Change 17(2):218-227. https://doi.org/10.1016/j.gloenvcha.2006.08.001

Tonmoy, F. N., A. El-Zein, and J. Hinkel. 2014. Assessment of vulnerability to climate change using indicators: a meta-analysis of the literature. Wiley Interdisciplinary Reviews: Climate Change 5 (6):775-792. https://doi.org/10.1002/wcc.314

Tschakert, P. 2007. Views from the vulnerable: understanding climatic and other stressors in the Sahel. Global Environmental Change 17:381-396. https://doi.org/10.1016/j.gloenvcha.2006.11.008

Turner, B. L., R. E. Kasperson, P. A. Matson, J. J. McCarthy, R. W. Corell, L. Christensen, N. Eckley, J. X. Kasperson, A. Luers, M. L. Martello, C. Polsky, A. Pulsipher, and A. Schiller. $2003 a$. A framework for vulnerability analysis in sustainability science. Proceedings of the National Academy of Sciences 100 (14):8074-8079. https://doi.org/10.1073/pnas.1231335100

Turner, B. L., P. A. Matson, J. J. McCarthy, R. W. Corell, L. Christensen, N. Eckley, G. K. Hovelsrud-Broda, J. X. Kasperson, R. E. Kasperson, A. Luers, M. L. Martello, S. Mathiesen, R. Naylor, C. Polsky, A. Pulsipher, A. Schiller, H. Selin, and N. Tyler. 2003b. Illustrating the coupled human-environment system for vulnerability analysis: three case studies. Proceedings of the National Academy of Sciences of the United States of America 100(14):8080-8085. https://doi.org/10.1073/pnas. 1231334100

Ulrich, W. 1987. Critical heuristics of social systems design. European Journal of Operational Research 31(3):276-283. https:// doi.org/10.1016/0377-2217(87)90036-1

Ulrich, W. 1995. Critical heuristics of social planning: A new approach to practical philosophy. Wiley, Hoboken, New Jersey, USA.

Vidal Merino, M., D. Sietz, F. Jost, and U. Berger. 2019. Archetypes of climate vulnerability: a mixed-method approach applied in the Peruvian Andes. Climate and Development 11 (5):418-434. https://doi.org/10.1080/17565529.2018.1442804

Vincent, K., S. Carter, A. Steynor, E. Visman, and K. L. Wågsæther. 2020. Addressing power imbalances in coproduction. Nature Climate Change 10:877-878. https://doi. org/10.1038/s41558-020-00910-W

Voinov, A., and F. Bousquet. 2010. Modelling with stakeholders. Environmental Modelling and Software 25(11):1268-1281. https:// doi.org/10.1016/j.envsoft.2010.03.007

Weißhuhn, P., F. Müller, and H. Wiggering. 2018. Ecosystem vulnerability review: proposal of an interdisciplinary ecosystem assessment approach. Environmental Management 61(6):904-915. https://doi.org/10.1007/s00267-018-1023-8

Whitney, C. K., N. J. Bennett, N. C. Ban, E. H. Allison, D. Armitage, J. L. Blythe, J. M. Burt, W. Cheung, E. M. Finkbeiner, M. Kaplan-Hallam, I. Perry, N. J. Turner, and L. Yumagulova. 2017. Adaptive capacity: from assessment to action in coastal social-ecological systems. Ecology and Society 22(2):22. https:// doi.org/10.5751/ES-09325-220222

Wyborn, C., A. Datta, J. Montana, M. Ryan, P. Leith, B. Chaffin, C. Miller, and L. van Kerkhoff. 2019. Co-producing sustainability: reordering the governance of science, policy, and practice. Annual Review of Environment and Resources 44:319-346. https://doi.org/10.1146/annurev-environ-101718-033103 